City University of New York (CUNY) CUNY Academic Works

9-2017

\title{
Criminal Responsibility: Meta-analysis and Study Space
}

Lauren E. Kois

The Graduate Center, City University of New York

\section{How does access to this work benefit you? Let us know!}

More information about this work at: https://academicworks.cuny.edu/gc_etds/2367

Discover additional works at: https://academicworks.cuny.edu

This work is made publicly available by the City University of New York (CUNY).

Contact: AcademicWorks@cuny.edu 


\section{CRIMINAL RESPONSIBILITY: META-ANALYSIS AND STUDY SPACE \\ by \\ LAUREN ELIZABETH KOIS}

A dissertation submitted to the Graduate Faculty in Psychology in partial fulfillment of the requirements for the degree of Doctor of Philosophy, The City University of New York 
(C) 2017

\section{LAUREN ELIZABETH KOIS}

All Rights Reserved 
Criminal Responsibility: Meta-Analysis and Study Space

by

\section{Lauren Elizabeth Kois}

This manuscript has been read and accepted for the Graduate Faculty in Psychology in satisfaction of the dissertation requirement for the degree of Doctor of Philosophy.

Date

Date

Richard Bodnar

Executive Officer

Supervisory Committee:

L. Thomas Kucharski

Steven Penrod

Patricia Zapf

Ira Packer

Janet I. Warren 


\begin{abstract}
Criminal Responsibility: Meta-Analysis and Study Space
\end{abstract}

by

\title{
Lauren Elizabeth Kois
}

\section{Advisor: Preeti Chauhan}

Criminal responsibility (CR; i.e., sanity) has garnered significant research attention over the years. While some variables predicting insanity outcomes are consistent, others are not. Study-level characteristics, such as sample selection, variability in the operational definition of insanity, or other unknown influences may explain discrepant findings. It is critical to consolidate these variables and systematically assess differences in methodology to understand the state of the literature and to guide future research. As such, I conducted the first metaanalysis and study space analysis (see Malpass et al., 2008) in this area. Only 16 studies met inclusion criteria for the meta-analysis. Summary effects indicated that older age, female sex, educational attainment, and unemployment were associated with insanity. Those classified insane more often had a psychiatric treatment history and psychotic disorder diagnosis. Finally, individuals opined or found insane were less likely to have a criminal history but more likely to have been opined incompetent to stand trial in the past. Notably, overall summary effects could mask important differences among studies, in that many effect sizes varied significantly according to study-level characteristics. Study space analyses $(N=7)$ revealed a dearth of literature that comprehensively addressed theoretically important variables in the context of various CR outcomes (e.g., defendant opined insane by evaluator or court, CR legal tests). Taken together, the project provides a comprehensive, empirical analysis of the CR literature and a systematic call for future research. 


\section{ACKNOWLEDGMENTS}

I thank members of this Dissertation Committee, Drs. Preeti Chauhan, L. Thomas Kucharski, Ira Packer, Steven Penrod, Janet I. Warren, and Patricia Zapf, for providing their time, expertise, and guidance.

Thank you also to Mom and Julia, who are the most independent and forever hardworking women anyone will ever meet. My Plan 9 guy, Steve, for selflessly getting in the New York Groove, hitting it out of the park in Bull Durham, and rolling with the Crimson Tide. Jen, LG, and Zoe: we might be finished, but we'll always have Whole Foods. Sarah and Lindsay for their dance moves and best friendships. Kelly and Calexico, my favorite date. The Carroll Gardens crew and affiliates, as there would not be as many laughs or bad Australian impressions without you all. My mentor Jessica who got me into this whole forensic business in the first place. C\&O. Gabrielle and my Prune family ("thorough and excellent, even in the dark, and even when no one is looking"). Cava, thank you for spending so much time with me-you really pulled me through. Dr. Warren's consideration and generosity. Patty, who taught and advised and always keeps it real. Superwoman Angela, who believed in me and sets an example in so many ways. Bob, you could not have given me a better opportunity and I am so fortunate to have learned from you. Eric for his "right-time" mentorship. Nicole, my "Federal" confederate.

Most of all, Preeti. You would not give away the answers and I know it made me better. Thank you. 


\section{Table of Contents}

Abstract

Acknowledgments

V

Table of Contents

vi

List of Tables and Figures

vii

Introduction

1

Presenting Problem

Proposed Studies

Methods

10

Meta-Analytic Results

16

Study Space Results

38

Discussion

40

References

58 
List of Tables and Figures

Table 1. Study Level Characteristics $\quad 12$

Table 2. Study Descriptors of All Included Studies 18

Table 3. Sample Characteristics for All Included Studies 20

Table 4. Insane and Insane Subsample Characteristics Across Studies 22

Table 5. Meta-Analytic Results $\quad 24$

Table 6. Study Space Analysis: Defendant Characteristics by CR Outcomes 38

Figure 1. Forest Plots: Age meta-analyses $\quad 25$

$\begin{array}{ll}\text { Figure 2. Forest Plots: Sex meta-analyses } & 27\end{array}$

Figure 3. Forest Plots: Race meta-analyses $\quad 28$

Figure 4. Forest Plot: Education meta-analysis 29

Figure 5. Forest Plot: Employment meta-analysis $\quad 30$

Figure 6. Forest Plots: Marital status meta-analyses 31

Figure 7. Forest Plot: Treatment history meta-analysis 32

Figure 8. Forest Plots: Diagnosis meta-analyses 33

Figure 9. Forest Plots: Criminal history meta-analyses 35

Figure 10. Forest Plot: Offense meta-analysis 36

Figure 11. Forest Plot: Competency evaluation history meta-analysis 37

Figure 12. Forest Plot: Incompetency history meta-analysis 37 


\section{Introduction}

The essence of criminal responsibility (CR, i.e., sanity) dates back to the Code of Hammurabi, with a building consensus over the centuries that individuals who lack mens rea (criminal intent) at the time of wrongdoing should not be punished for actus reus (criminal behavior; see Shen, Hoffman, Jones, Greene, \& Marois, 2011). Stated differently, individuals should not be held criminally responsible when there was no intention of wrongdoing. This ideal has persisted throughout English Common Law and influenced the conceptualization of CR in the United States (Blackstone, 1979). While the general concept of CR has remained the same, specific legal tests of CR have varied over time and across U.S. jurisdictions.

\section{CR Legal Tests}

U.S. courts have undergone several CR test iterations. However, the two most prominent insanity criteria in place today are loosely those of M'Naghten and the American Law Institute (ALI, Model Penal Code, 1962). In general, defendants meeting M'Naghten criteria must have, on account of mental disease or defect, lacked the cognitive capacity to understand what they were doing or to distinguish right from wrong at the time of the offense (see Queen $v$. M'Naghten, 1843). ALI criteria afford more flexibility in the defense: defendants meeting ALI or variant criteria lacked cognitive capacity or volitional capacity to conform their behavior to the law as an artifact of their mental illness. Some posit that insanity defense reform, such as the introduction of more strident legal tests of CR and the introduction of the Guilty But Mentally Ill (GBMI) verdict, has not lead to significant changes in insanity plea and acquittal rates, as was the intention of law-makers (Melville \& Naimark, 2002; Steadman, McGreevy, Morrissey, Callahan, \& Robbins, 1993). Indeed, we know from experimental research that nuances in legal 
tests of CR may be "much ado about nothing" (Finkel, 1989). Melton et al. (2007), in their critique of insanity defense reform, go as far to call variants of insanity tests "guises (p. 201)."

\section{Raising the Issue}

Very few defendants raise the question of CR, with base rate estimates ranging from $0.3 \%$ to $8 \%$ among felony cases (Steadman et al., 1993). Defendants who seek the insanity defense undergo an evaluation in which a forensic mental health professional conducts a retrospective inquiry into how defendants' psychiatric impairment at the time of the offense may have impaired their cognitive and/or volitional capacities, specific to the CR legal test of that jurisdiction (Packer, 2009). Evaluators submit their CR opinions to the retaining party (defense, prosecution, or court) and fact-finders (i.e., judges or jurors) draw the ultimate CR opinions. Typically, evaluators' opinions and legal verdicts provide data for conducting CR research. Notably, these outcomes - evaluators' opinions and legal verdicts - are not one and the same, as it is fact-finders, not evaluators, who have the final say with respect to verdict type. This is reflected in the differing base rates of insanity: evaluators, on average, opine about $10 \%$ of referred defendants insane (Cochrane, Grisso, \& Frederick, 2001; Johnson, Nicholson, \& Service, 1990; Warren, Rosenfeld, Fitch, \& Hawk, 1997; Warren, Murrie, Chauhan, Dietz, \& Morris, 2004), whereas the court acquits anywhere from $1 \%$ to $50 \%$ of insanity defendants, although this base rate typically falls around 25\% of pleas (McGinley \& Pasewark, 1989; Steadman et al.). Potentially, attorneys may be discouraged to pursue an insanity defense in cases where evaluators opined a defendant sane, and so defendants who have a significant chance of acquittal (according to evaluators' opinions) are more likely to plea insanity. In support of this speculation, Rogers, Seman, and Stampley (1984) found that, in their regression model, evaluators' opinions of insanity were the only factor significantly influencing the courts' finding 
after accounting for defendant's race, sex, educational attainment, diagnosis, treatment history, and crime type. Importantly, while research adopting one outcome measure, such as evaluators' opinions, may not be generalized to fact-finders' opinions, the combined body of research provides insight into which defendant characteristics are associated with CR outcomes.

\section{Correlates of CR Outcomes}

Compared to other areas of forensic assessment, there is a dearth of empirical literature on CR. This is most likely due to the low base rate of insanity pleas, leaving fewer defendants eligible for study. What is evident from the relatively small body of research is that predictors of evaluators' opinions of insanity and insanity acquittals are sometimes inconsistent. What follows is a review of demographic, clinical, and legal characteristics and their relationships to CR.

Demographic characteristics. Thus far, research regarding defendants' age is mixed. While some have found older defendants are more likely to be acquitted or opined insane (Cirincione, Steadman, \& McGreevy, 1995; Johnson et al., 1990; Pasewark, Jeffrey, \& Bieber, 1987 [herein Pasewark et al., 1987b]; Warren et al., 2004), others identified no relationship between these two variables (Boehnert, 1987; Daniel, Beck, Herath, Schmitz, \& Menninger, 1984; Nestor and Haycock; 1997; Packer, 1987; Rogers et al.,1984). Notably, varying outcome criterion across studies (legal tests; evaluator opinion versus fact-finder) may moderate these findings.

$\mathrm{CR}$ research regarding defendant sex is relatively scarce. This is likely attributed to the fact that males are more likely to be arrested than females (Snyder, 2012), and as a result females comprise less of the defendant population who plead insanity. Thus, female defendants who plead insanity are relatively rare, making the study of sex differences a significant challenge for researchers. Those who have had the opportunity to compare CR outcomes across defendant sex 
identified somewhat of a consensus. Studies report a significant effect for sex, with females more likely than males to be opined or found insane (Cirincione et al., 1995; Warren et al., 2004). Rogers et al. (1984) found that evaluators' opinions did not share a significant relationship with defendant sex, while the courts more often acquitted females insane. This finding underscores the importance of considering outcome measure - evaluator opinion or that of the courts'—when synthesizing CR research.

The relationship between race/ethnicity and CR outcomes is more inconsistent, with studies divided on whether Whites or non-Whites are more likely to be found insane (Boehnert, 1989; Cirincione et al., 1995; Daniel et al., 1984; Johnson et al., 1990; Warren et al., 2004). These variable findings may be due to jurisdictional factors, as suggested by Cirincione et al. In their study of eight state jurisdictions, they found race was not significant in the majority of jurisdictions included in their study, but two jurisdictions-Georgia and Ohio-were significantly more likely to find Blacks insane. Rogers et al. (1984) found, after accounting for other variables, race was not a significant factor in predicting CR outcomes. Although it appears race/ethnicity is not a robust predictor of CR outcomes, clarification of why it is relevant in some cases but not in others (e.g., Cirincione et al.) deserves research attention.

Some authors found defendants with increased educational attainment are at a higher likelihood of being found insane (Cirincione et al., 1995; Daniel et al., 1984; Pasewark et al., 1987b; Rogers et al., 1984). Still other researchers identified no association between markers of education or intelligence and CR outcomes (Boehnert, 1985; Nestor and Haycock, 1997). Pasewark, Bogenberger, Gudeman, and Bieber (1987; herein Pasewark et al., 1987a) found significant effects for employment history, in that unemployed defendants were more likely to be 
opined insane. Cirincione et al. found unmarried defendants were more often found insane, while Daniel et al. found no significant relationship.

Clinical characteristics. Defendants with a significant psychiatric history are more often found insane (Cirincione et al., 1995; Daniel et al., 1984; Packer, 1987; Pasewark et al., 1987a; Pasewark et al., 1987b; Rogers et al., 1984; Warren et al., 2004). Research is mostly consistent with respect to defendant diagnosis, in that those who carry a diagnosis of psychotic disorder are more often found insane (Cirincione et al.; Daniel et al.; Johnson et al., 1990; Nestor \& Haycock, 1997; Packer, 1987; Pasewark et al., 1987b; Rogers et al., 1984; Warren et al.). Only one study has reported no effect for psychosis (Caldwell, Mandracchia, Ross, \& Silver, 2003). In general, these findings are encouraging, as severe and persistent mental illnesses are usually requisite for a successful insanity defense. Taken together, patterns in treatment history, diagnosis, and CR outcome are in line with clinical and legal theory.

Legal characteristics. Whether or not defendants with a criminal history are more likely to be found insane is unclear. Some researchers found no differences in outcome according to this variable (Boehnert, 1989; Heilbrun et al., 1988; Pasewark et al., 1987b) while others have found that defendants without such a history are more likely opined insane (Daniel et al., 1984; Packer et al., 1987; Warren et al., 2004). This could be tied to jurisdictional standards, as Cirincione et al. (1995) discovered the impact of criminal history on insanity acquittals varied across states in their study. Cirincione and colleagues also found defendants charged with violent crimes were more likely to be found insane, as had past researchers (Johnson et al., 1990).

Competence to stand trial (CST), the most commonly raised psycholegal question (Melton et al., 2007), is similar to CR in that it is influenced by defendants' psychiatric presentation. However, while CR concerns defendants' retrospective behavior, competency 
concerns defendants' present understanding of their charges and ability to assist counsel in their defense (Dusky v. United States, 1960). Likely because of the significant effect severe mental illness can have on both Dusky and CR psycholegal abilities, research indicates that CST and CR are closely linked. In Daniel et al.'s (1984) study, incompetence and insanity shared a robust relationship ( $r=0.69)$. Boehnert (1989) found that defendants acquitted insane were more likely to have been found incompetent in the past. Emerging data has helped to further elucidate the relationship of CST and CR (Chauhan, Warren, Kois, \& Wellbeloved-Stone, 2016). Findings indicated that, relative to defendants who were evaluated for CR alone, defendants evaluated for both CST and CR were at an increased likelihood to be opined insane.

\section{Presenting Problem}

Defendants found insane can be indefinitely committed for a period of time that extends beyond that of a guilty incarceration sentence (Jones v. United States, 1983). Those found guilty may be incarcerated for a substantial amount of time and may even be eligible for the death penalty. Despite these grave circumstances and a history of public controversy (Melton et al., 2007; Steadman et al., 1993), research on insanity is underexplored, most likely due to the low base rate of insanity pleas.

At present, we cannot make many generalizations across the CR literature and it is unclear whether predictors of CR outcomes vary due to differences in outcome criteria (legal tests, evaluator versus court opinions), sample characteristics, sampling error, combinations of these variables, or other unknown reasons. An important methodological issue is that of "sane" research comparison groups, which could influence CR research findings. Zapf, Green, and Rosenfeld (2011) noted that researchers sometimes incorporate "pure" sane comparison groups, i.e., non-psycholegal incarcerated inmate samples that presumably never raised the insanity 
defense or civil psychiatric patients, into CR research. While this approach may be appropriate for specific research questions — such as examining differences between committed acquittees and civil inpatients, for example — it may not be the best means to investigate differences between individuals classified as "sane" or "insane." As Zapf et al. summarized, considering the non-psycholegal samples largely isolates criminal behavior from mental illness, and to utilize one sample or the other is to dismiss half of the clinical-forensic picture. Analyses that consider the impact of these sampling approaches are needed. In addition, a systematic frequency analysis of which variables have been studied in combination (e.g., diagnosis, CR standard, and provider of CR opinion [evaluator or court]) would be helpful in assessing the thoroughness of the literature, identifying potential confounds, and guiding future research.

\section{Meta-analysis}

Meta-analysis is a method of secondary analysis that accumulates data across individual studies. Typically, meta-analytic methods allow for the measurement of population effects by accounting for study-level methodological differences, such as varying legal criteria among CR research. This approach is superior to null hypothesis testing for individual studies, as it allows for calculation of overall summary effects for all eligible studies on a given topic (for example, the diagnosis-CR outcome relationship) and helps to illuminate the importance of various methodological considerations (Howard, Maxwell, \& Fleming, 2000). Whereas large sample sizes can inflate significance levels and influence surface-level interpretation of findings, in meta-analysis, effect sizes are functions of sample size and significance level. Meta-analysis also increases power to detect significant differences (Cohn \& Becker, 2003), which should be especially appealing to CR researchers who frequently only have small sample sizes for study. 
Another benefit of meta-analysis is that it takes into consideration the issue of publication bias. While a number of CR studies demonstrate a significant relationship between psychotic symptoms and an insanity opinion or outcome, there may be a number of unpublished studies that identify no such relationship (e.g., in line with Caldwell et al., 2003's finding that psychotic symptoms were not tied to insanity outcomes), which would not align with psycholegal theory and warrant close consideration. One study found that only $4 \%$ of reports in which significant relationships were not identified were published, suggesting that null findings are rarely published (Cooper, DeNeve, \& Charlton, 1997). This “file drawer" phenomenon can lead to faulty inferences. This issue has the potential to be widespread in research on insanity, as small sample sizes are associated with lower power and potentially a lack of significant findings. Metaanalysis takes this issue into consideration by examining degrees of publication bias. Taken together, meta-analysis can be more informative than "vote counting" through a narrative systematic review (Sporer \& Cohn, 2011).

\section{Study Space Analysis}

Study space analysis, first proposed by Malpass et al. (2008) as a way to guide public policy, is a method of quantifying variables that have been studied in a given research domain. The organization of a study space — essentially, a systematic frequency table — clearly depicts which variables have been studied alone and in combination. Gaps in the literature are identified by this method, thereby highlighting study topics that are in need of replication or new research attention. Study space as applied to CR research would be particularly useful in identifying which predictor variables, such as defendant's race, have been studied along with specific legal tests of CR as outcomes. Together, these features allow for a clear view of whether or not a field of research is saturated and if comprehensive conclusions from the literature are permitted. 
Furthermore, Malpass et al. (2008) reasoned that study space analysis should only include published studies because, as noted by Deffenbacher, Bornstein, Penrod, and McGorty (2004), "the legal standards for proffered scientific testimony established by the U.S. Supreme Court in Daubert ... have strengthened the preference by the legal system for meta-analytic conclusions based on a body of well conceived, well executed, and easily retrievable studies" (p. 692). Given CR's legal context, an analysis of studies eligible for Daubert inclusion (see Daubert v. Merrell Dow Pharmaceuticals, 1993) would be helpful.

Although systematic reviews and meta-analyses are necessary, they focus on what we know now, rather than what we need to know. The contribution of a study space analysis is unique relative to a systematic review or meta-analysis in that it concentrates on future findings, rather than those presently available. Thus, study space analysis is a novel approach that would evaluate the comprehensiveness of the CR literature and provide directions for future research, if needed. Findings would have relevance for practitioners and policy makers alike.

\section{Proposed Studies}

This project sought to empirically consolidate CR research by conducting the first metaanalysis in this area. This task is beneficial to law and psychology scholars, researchers, clinicians, and the courts, as it may provide a central location to summarize a complex body of research that is sometimes in conflict. Based on past research (Cochrane et al., 2001; Johnson et al., 1990; McGinley \& Pasewark, 1989; Pasewark et al., 1987; Steadman et al., 1993; Warren et al., 2004), I hypothesized the insanity base rate of defendants evaluated for insanity would be approximately $10 \%$, and those who officially raised the defense would be acquitted approximately $25 \%$ of the time. As research suggests that indicators of clinical impairment have the most robust relationships with insanity outcomes, I also proposed that defendants diagnosed 
with psychotic disorders and who carried a psychiatric history would more often be opined or found insane than their counterparts.

By following the meta-analysis with the first study space analysis of CR research, findings will inform the psycholegal community of strengths and limitations in this literature and provide recommendations for future study. Given the many studies considering clinical characteristics, I anticipated defendant psychiatric history and diagnosis would be the most frequently explored variables among the CR literature as identified in the study space.

\section{Methods}

\section{Meta-Analysis}

Study eligibility. Studies included in the meta-analysis and study space compared U.S. defendants referred for CR evaluations and opined insane or sane by evaluators or those who plead insanity at trial and were acquitted insane or found sane (guilty). In addition, studies utilizing non-psycholegal comparison groups of civil psychiatric or "pure" incarcerated groups (i.e., those convicted of crimes who never plead insanity) were incorporated into the analyses. Grey literature, in the form of unpublished theses and dissertations, were eligible for the metaanalysis. Studies must have provided sufficient data to calculate at least one effect size to be eligible. In cases where one study led to multiple reports, only reports with the largest cumulative sample sizes and the largest number of calculable effect sizes were included.

Excluded were interrater reliability studies, studies with insanity acquittee conditional release samples, and data collected prior to the enactment of 1962's Model Penal Code. Per Lipsey and Wilson's (2001) recommendations, studies providing correlation coefficients for effect sizes measures without raw data were excluded, the reason being this metric is inappropriate for research involving low outcome base rates, as in CR research. 
Literature search. The first step of the literature review began by searching PsycINFO using keywords criminal responsibility, insanity, and guilty but mentally ill. These terms were selected to maximize sensitivity (number of relevant reports/total number eligible) and precision (relevant/identified). “Gold standard” CR texts (e.g., Melton et al., 2007; Packer, 2009) were referenced. Web of Science was used to identify subsequent citations. A call for studies was also submitted to PSYLAW, a forensic psychology interest online listserve. Three CR experts were contacted via email and asked to assess the list of considered studies. One responded, provided an additional reference, and subsequently judged the list of studies as complete. Ultimately, 2,003 references were reviewed for eligibility: $N=16$ met criteria for the meta-analysis, while $N$ $=7$ met criteria for the study space. The majority of excluded studies were case law commentary, studies conducted outside of the United States, mock jury studies, and those that did not provide sufficient statistics to calculate at least one effect size for the variables of interest. No eligible studies included a GBMI verdict, and so this outcome was not further considered. Eligible studies are accompanied by their respective study-level characteristics in Table 1. 
Table 1. Study Level Characteristics.

\begin{tabular}{|c|c|c|c|c|c|c|c|c|}
\hline & $\begin{array}{l}\text { Publication } \\
\text { Type }\end{array}$ & $\begin{array}{c}\text { Insane } \\
\text { Comparison } \\
\text { Group } \\
\end{array}$ & $\begin{array}{c}\text { Sane Comparison } \\
\text { Group }\end{array}$ & $\begin{array}{l}\text { Included } \\
\text { Females }\end{array}$ & $\begin{array}{l}\text { Included } \\
\text { CST }\end{array}$ & Setting & Jurisdiction & $\begin{array}{c}\text { CR } \\
\text { Standard }\end{array}$ \\
\hline Boardman (1996) & Dissertation & Acquitted & Plead/convicted & Yes & Yes & Outpatient & $\mathrm{OH}$ & Other \\
\hline Boehnert (1989) & Article & Acquitted & Plead/convicted & No & No & Mixed & FL & M'Naghten \\
\hline Hays (1999) & Dissertation & Acquitted & Other & Yes & No & - & $\mathrm{CA}$ & M'Naghten \\
\hline Heilbrun \& Heilbrun (1989) & Article & Acquitted & Incarcerated & No & No & Mixed & GA \& FL & Other \\
\hline Howard \& Clark (1985) & Article & Acquitted & Plead/convicted & Yes & Yes & Mixed & MI & ALI \\
\hline Johnson et al. (1990) & Article & Referred & Referred & Yes & Yes & Inpatient & MI & M'Naghten \\
\hline Linhorst \& Turner (1999) & Article & Acquitted & Civil psychiatric & Yes & No & Inpatient & MO & M'Naghten \\
\hline Moskowitz et al. (1999) & Article & Acquitted & Civil psychiatric & Yes & No & Inpatient & VA & ALI \\
\hline Nestor \& Haycock (1997) & Article & Acquitted & Other & No & No & Inpatient & MA & ALI \\
\hline Packer (1987) & Article & Acquitted & Plead/convicted & Yes & Yes & Inpatient & MI & ALI \\
\hline Pasewark et al. (1987a) & Article & Acquitted & Plead/convicted & Yes & Yes & - & $\mathrm{HI}$ & ALI \\
\hline Pasewark et al. (1987b) & Article & Acquitted & Plead/convicted & No & No & Inpatient & $\mathrm{CO}$ & M'Naghten \\
\hline Powell (1998) & Dissertation & Referred & Referred & Yes & Yes & Mixed & MO & ALI \\
\hline Sreenivasan et al. (1997) & Article & Acquitted & Other & No & No & Mixed & $\mathrm{CA}$ & M'Naghten \\
\hline Veysey (1993) & Dissertation & Acquitted & Plead/convicted & Yes & Yes & Other & Various & Other \\
\hline Warren et al. (2004) & Article & Referred & Referred & Yes & Yes & Mixed & VA & M'Naghten \\
\hline
\end{tabular}

Note - Missing. Acquitted = Defendants who plead insanity and were acquitted. Referred = Defendants referred for CR evaluation. Plead/convicted $=$ Defendants who plead insanity and were convicted. Incarcerated = Incarcerated offenders who presumably never plead insanity. ALI = American Law Institute standard or variant. M'Naghten = M'Naghten standard or variant. 
Data extraction. Coding forms and manuals were adapted from Pirelli, Gottdiener, and Zapf's CST meta-analysis (2011). Pirelli and colleagues' construct is in some ways comparable to insanity, as many of the predictor variables are similar and predictors and outcomes are usually reported categorically (such as, "defendants diagnosed with a psychotic disorder are more likely to be found insane"). Prior to data extraction, the author reviewed eligible studies and incorporated additional variables into the coding form as appropriate. All studies were triplecoded by the author and five studies were double-coded by a Master's level research assistant. Coders met to assess interrater reliability for the five overlapping studies. For the 46 categorical variables, percent agreement was $97.8 \%$ and Cohen's kappa $=96.8$. For the 321 continuous variables, percent agreement was $96.0 \%$ with an intra class coefficient (ICC) of $r=1.00, p<$ .001 . Note that the ICC is likely inflated because of the number of variables included in the coding protocol. Coders met to address coding discrepancies in order to meet complete agreement for all dually coded data.

Study-level descriptors included years of data collection $(M$ and $S D)$, publication year, type of publication (article/dissertation), “insane” comparison group (evaluatee/acquittee), "sane" comparison group (evaluatee, plead insanity and convicted, "pure" incarcerated, civil psychiatric, or other), whether the study included females, whether combined competency to stand trial evaluations were included (yes/no), study setting (inpatient, outpatient, mixed, or other), and insanity standard (M'Naghten or variant, ALI or variant, or Other).

We coded 12 variables for meta-analytic comparison. For consistency, we coded raw data ( $M, S D$, and frequencies) when possible. Effect sizes ( $d$, chi-square, and $t$, along with $p$ values) were coded when raw data could not be derived from reports. Age was the only continuous predictor. While I planned to include scores on intelligence measures, several authors screened 
out defendants with scores two standard deviations from the mean (i.e., IQ < 70). This method likely resulted in skewed data that was not representative of the defendant population. For this reason, intelligence measure scores were not included.

Demographic categorical predictor variables included sex (male/female), race (White/Non-White), education (completed high school/did not complete high school), employment status (employed/unemployed), and marital status (married/unmarried). It would be ideal to code a range of races; however, authors differed in their consideration of race/ethnicity. For example, the majority of groups coded race as White/Non-White, while others coded race as White, Black, and “Other" races. As such, dichotomization of the race variable as White/NonWhite provided the cleanest data extraction.

Clinical categorical predictors included psychiatric history and diagnosis. Authors varied in their operationalization of psychiatric treatment history, with several considering past outpatient history and many considering past inpatient hospitalization. To gather an optimal number of studies for the analyses, we coded for any psychiatric history (prior psychiatric treatment/no prior psychiatric treatment). It was an initial goal to code primary diagnoses on multiple levels - for example, psychotic disorder, mood disorder, anxiety disorder, substance abuse disorder, personality disorder, and so on. However, reports frequently dichotomized diagnosis as psychotic versus not psychotic. They also coded for co-occurring diagnoses or had discrepant means of collapsing diagnostic categories. As a result, it was necessary to dichotomize diagnosis as psychotic/not psychotic.

Likewise, authors operationalized criminal history in a variety of forms, including prior arrest, number of arrests, prior violent offense, prior conviction, prior felony conviction, severity of charges, and "rationality" of offense. The dispersion was so wide there was no clear consensus 
on the best way to operationalize this variable. To provide an indicator of criminal history, we coded for any criminal history as opposed to no criminal history. Current violent offense was dichotomized as violent/non-violent. Finally, we coded whether defendants were evaluated for competency to stand trial, and if so, whether they were classified as incompetent or competent.

Analytic plan. Borenstein et al.'s (2009) recommendations guided the analytic approach. Study-level and sample descriptive statistics were calculated in SPSS v. 24. All meta-analytic findings were produced with Comprehensive Meta-analysis V2 (CMA; Borenstein, Hedges, Higgins, \& Rothstein, 2005). CMA calculated the standardized mean difference (Cohen's $d$ ) for age, along with its $95 \%$ confidence interval $(95 \% \mathrm{CI})$ and $p$ value. Odds ratios (ORs) and their respective $95 \%$ CIs and $p$ values were calculated for categorical variables. The term cases was used to indicate members of "pure" incarcerated, civil psychiatric, or other non-psycholegal group members, relative to evaluatee or trial defendants. In order to assess the validity of incorporating non-psycholegal cases into our understanding of predictors of insanity, I first calculated effect sizes for all studies and then again for those only including defendants evaluated for CR or who plead insanity at trial. Therefore, 24 comparisons (12 variables of interest x 2 comparisons each) were anticipated. Although Bonferroni-corrections are recommended when conducting multiple comparisons, they also reduce the chance of detecting significant effects. Consequently, in light of the dearth of CR research and the foresight that few studies would be incorporated, I adopted a standard significance level of $p<.05$ to detect significant effects.

Given the variability in CR study methodology, it was assumed the magnitude of predictor-outcome relationships (i.e., effect sizes) were not identical across studies. Therefore, a 
random effects meta-analysis was appropriate. Two statistics were calculated to evaluate the variability in effect sizes (termed heterogeneity) across studies: $Q$ and $I^{2}$ statistics.

The $Q$ statistic, essentially a sum of heterogeneity across studies, helps to assess summary effect variability according to specific study-level characteristics. Significant $Q$ values typically lead to moderator analyses (termed subgroup analyses), which allow the meta-analyst to determine whether study-level characteristics significantly impact summary effects. However, subgroup analyses are only possible when the number of studies available is adequate. The Cochrane Collaboration recommends at least 10 studies per subgroup in order to draw confident conclusions from subgroup analyses; otherwise, sample size is inadequate (Higgins \& Green, 2008). Multivariate findings derived from an insufficient number of studies are not only spurious, but also potentially misleading. Given the small number of studies eligible for this meta-analysis, subgroup analyses were not pursued.

Nevertheless, even minimal insight into study heterogeneity can shed light on whether summary effects are consistent across studies, which can prompt important research questions about methodological approach and its impact. While $Q$ statistics are informative, their power to detect heterogeneity is a function of sample size (Borenstein et al., 2009). Thus, relying on $Q$ alone would prove problematic in these analyses. To provide a better understanding of the relevance of methodological considerations in the CR research, $I^{2}$ statistics (see Higgins, Thompson, Deeks, \& Altman, 2003) were used as indicators of inconsistency in findings across studies. $I^{2}$ is a standardized descriptive statistic used to represent overlap in effect size CIs not due to chance. Stated differently, they indicate whether heterogeneity is due to meaningful differences between study characteristics, whereas $Q$ statistics simply indicate whether general heterogeneity (study error along with methodological differences) is present. $I^{2}$ provides an 
intuitive measure of heterogeneity. For example, an $I^{2}=80 \%$ would indicate $80 \%$ of heterogeneity is not attributable to chance, and instead likely due to methodological considerations. Higgins et al. labeled $I^{2}$ values of $25 \%, 50 \%$, and $75 \%$ as low, moderate, and high levels of inconsistency, respectively. The higher the $I^{2}$ value, then, the less we can assume generalizability of a summary effect across studies.

Finally, fail-safe Ns were calculated to assess publication bias for each summary effect. Fail-safe Ns identify the number of reports with null results needed to negate a significant summary effect. Larger fail-safe $N$ values indicate greater confidence in findings. For instance, a fail-safe $N$ of 50 would imply good confidence a summary effect is robust, while a value of 2 would indicate an unstable and ultimately weak finding. Additional methods of measuring publication bias, such as the trim and fill approach, were not appropriate here due to the small number of eligible studies.

\section{Study Space}

I adapted Malpass et al.'s (2008) methodology by arranging the study space with frequently studied defendant characteristics as rows and outcome variables as columns. Outcomes were categorized by jurisdictional standard (ALI or variant and M'Naghten or variant) and CR opinion source (evaluator versus court), with jurisdictional standard as superordinate. Individual cells each represented a specific variable combination (defendant characteristic x CR standard and opinion source). I tallied each occurrence of a given variable combination. Values were then summed to calculate variable combination frequencies.

\section{Meta-Analytic Results}

\section{Descriptive Statistics}

Study descriptors. Table 2 details descriptive statistics across the range of studies. 
Table 2. Study Descriptors of All Included Studies ( $=16)$.

\begin{tabular}{lc}
\hline Descriptor & $n$ studies (\%) \\
\hline Type of Publication & $12(75.0)$ \\
Article & $4(25.5)$ \\
Dissertation & \\
Type of insane comparison group & $13(81.2)$ \\
Acquitted insane at trial & $3(18.8)$ \\
Referred & \\
Type of sane comparison group & $7(43.8)$ \\
Plead/convicted & $3(18.8)$ \\
Referred & $3(18.8)$ \\
Other & $2(12.5)$ \\
Civil psychiatric & $1(6.3)$ \\
Incarcerated & \\
Included females & $5(31.3)$ \\
No & $11(68.7)$ \\
Yes & \\
Included CST evaluations & $7(43.8)$ \\
No & $9(56.2)$ \\
Yes & \\
Study setting & $6(42.9)$ \\
Inpatient & $6(42.9)$ \\
Mixed inpatient and outpatient & $1(7.1)$ \\
Outpatient & $1(7.1)$ \\
Other & \\
Jurisdiction & $16(100.00)$ \\
State & $0(0.00)$ \\
Federal & \\
Insanity standard & $7(43.8)$ \\
M'Naghten or variant & $6(37.5)$ \\
ALI or variant & $3(18.8)$ \\
Other &
\end{tabular}

The majority of studies were published empirical journal articles. Insane comparison groups were typically comprised of defendants acquitted insane at trial, with a small portion of studies incorporating evaluatee samples. There was more variability among type of sane comparison group, in that the majority of samples utilized defendants who plead insanity and convicted at trial, but evaluatees opined sane, "other," civil psychiatric patients, and incarcerated subsamples were also present. Approximately three-quarters included females, and about half 
included defendants evaluated for CST. Studies were equally divided among inpatient and "mixed" settings, meaning a combination of both inpatient and outpatient settings. All studies were conducted at the state jurisdictional level.

Several author groups did not explicitly state their adopted CR criteria. The majority of these could be deduced by study content and legal research. Heilbrun and Heilbrun (1989) stated defendants are not responsible if "mental condition renders them incapable of forming intent or exerting control over their impulses" (p. 39), which this author understood as an ALI standard or variant. However, review of legal statutes indicated Georgia allowed for M'Naghten impairment but also a separate "delusional compulsion" insanity defense, which in effect made for an ALI variant legal test. Therefore, the study was coded as Other. Two studies utilized samples with inter- or intra-jurisdictional differences. In Boardman's (1996) report, insanity criteria were amended during data collection. In Veysey's (1993) case, data were collected across eight jurisdictions with varying insanity criteria. Overall, there was noticeable variability among insanity standards across studies, with M'Naghten slightly at the forefront.

Sample characteristics. Eligible studies encompassed 19,903 cases, with 4,914 $(32.78 \%)$ considered insane. Sample characteristics are provided in Table 3. 
Table 3. Sample Characteristics for All Included Studies ( $\mathrm{N}=16)$.

\begin{tabular}{|c|c|c|c|}
\hline Characteristic & $n$ Studies & Mean & Range \\
\hline \multicolumn{4}{|l|}{ Study/Sample } \\
\hline Years of data collection & 14 & 1984.61 & $1973-1996$ \\
\hline Date of publication & 16 & 1993.69 & $1985-2004$ \\
\hline Total sample size $(n)$ & 16 & 1243.94 & $28.00-7398$ \\
\hline \multicolumn{4}{|l|}{ Base rate* } \\
\hline$\%$ Evaluator opinion & 3 & 13.55 & $9.38-30.14$ \\
\hline$\%$ Court opinion & 7 & 25.58 & $15.33-30.14$ \\
\hline \multicolumn{4}{|l|}{ Demographics } \\
\hline Age & 4 & 35.30 & $29.10-43.40$ \\
\hline \multirow[t]{2}{*}{$\%$ Male } & 14 (all studies) & 89.10 & $70.42-100.00$ \\
\hline & 9 (mixed sex) & 83.04 & $70.42-92.68$ \\
\hline$\%$ White & 12 & 63.48 & $35.37-90.00$ \\
\hline$\%$ Completed high school & 2 & 47.56 & $46.97-48.15$ \\
\hline$\%$ Unemployed & 4 & 58.84 & $6.67-75.33$ \\
\hline$\%$ Unmarried & 4 & 82.74 & $78.20-86.96$ \\
\hline \multicolumn{4}{|l|}{ Diagnosis } \\
\hline \% Psychotic Disorder & 12 & 43.54 & $20.46-73.20$ \\
\hline \multicolumn{4}{|l|}{ Psychiatric history } \\
\hline$\%$ Any psychiatric history & 7 & 57.38 & $14.08-79.70$ \\
\hline \multicolumn{4}{|l|}{ Criminal history } \\
\hline \% Any criminal history & 9 & 53.62 & $33.00-75.05$ \\
\hline$\%$ Violent instant offense & 8 (all studies) & 79.92 & $49.01-100.00$ \\
\hline$\%$ Violent instant offense & 4 (mixed offenses) & 59.84 & $49.01-69.07$ \\
\hline \multicolumn{4}{|l|}{ Competency to stand trial } \\
\hline $\begin{array}{l}\text { \% Previous CST } \\
\text { evaluation }\end{array}$ & 6 & 83.65 & $50.00-100.00$ \\
\hline$\%$ Previously IST & 6 & 27.77 & $2.08-56.67$ \\
\hline
\end{tabular}

Note. *For non-matched samples that were evaluated and/or plead insanity at trial.

The average year of publication was approximately 1994, with a 19-year publication date range.

On average, data were collected many years earlier, with an average of approximately 1985 and a range of 23 years. It should be underscored that referencing $M$ year here is misleading. Patterns of data collection were likely multimodal (as in Veysey, 1993), but there was no mechanism to calculate alternative measures of central tendency for this variable. Insanity base rates were calculated for studies that did not match sane and insane subgroup sample size. The mean base 
rate for defendants evaluated and opined insane was $13.55 \%(n=3, S D=5.84)$. The mean base rate of insanity for defendants acquitted at trial was $25.58 \%(n=7, S D=6.96)$.

On average, defendants were 35.30 years old. The vast majority of cases were male, regardless of whether all studies or only mixed-sex studies were considered. Over half were White. Approximately half completed high school or were unemployed at the time of the offense. The majority of cases were unmarried. Slightly less than half were diagnosed with a psychotic disorder, while slightly more than half had a psychiatric treatment history. Half of cases had a criminal history, and most were charged with violent offenses. Six studies noted that at least a portion of defendants was evaluated for CST and its outcome.

Descriptive comparisons between sane and insane subsamples are detailed in Table 4. 
Table 4. Insane and Insane Subsample Characteristics Across Studies (N = 16).

\begin{tabular}{|c|c|c|c|c|c|}
\hline \multirow[b]{2}{*}{ Characteristic } & \multirow[b]{2}{*}{$n$ studies } & \multicolumn{2}{|c|}{$\begin{array}{l}\text { Insane } \\
(n=4,914)\end{array}$} & \multicolumn{2}{|c|}{$\begin{array}{c}\text { Sane } \\
(n=14,989)\end{array}$} \\
\hline & & $M$ & Range & $M$ & Range \\
\hline \multicolumn{6}{|l|}{ Demographics } \\
\hline Age & 10 & 35.88 & $31.90-41.80$ & 33.81 & $27.90-47.10$ \\
\hline$\%$ Male (all studies) & 13 & 88.91 & $72.00-100.00$ & 87.32 & $57.14-100.00$ \\
\hline$\%$ Male (mixed samples) & 8 & 81.98 & $72.00-90.36$ & 79.40 & $57.14-91.49$ \\
\hline$\%$ White & 10 & 53.83 & $31.25-67.39$ & 62.18 & $38.00-82.86$ \\
\hline$\%$ Completed high school & 2 & 55.06 & $53.30-56.81$ & 44.86 & $42.80-46.92$ \\
\hline$\%$ Unemployed & 3 & 55.20 & $6.67-89.13$ & 54.54 & $6.67-96.86$ \\
\hline$\%$ Unmarried & 3 & 86.10 & $80.43-91.67$ & 85.25 & $78.50-91.43$ \\
\hline \multicolumn{6}{|l|}{ Diagnosis } \\
\hline$\%$ Psychotic Disorder & 12 & 74.79 & $54.26-100.00$ & 28.37 & $5.00-76.84$ \\
\hline \multicolumn{6}{|l|}{ Psychiatric history } \\
\hline$\%$ Any history & 7 & 71.65 & $22.43-100.00$ & 50.70 & $10.48-73.20$ \\
\hline \multicolumn{6}{|l|}{ Criminal history } \\
\hline$\%$ Any criminal history & 9 & 49.00 & $16.00-69.70$ & 55.49 & $43.04-77.41$ \\
\hline$\%$ Violent offense (all studies) & 9 & 74.59 & $39.47-100.00$ & 75.68 & $40.07-100.00$ \\
\hline$\%$ Violent offense (mixed) & 5 & 54.26 & $39.47-78.88$ & 56.23 & $40.07-70.10$ \\
\hline$\%$ Referred for CST evaluation & 6 & 89.25 & $67.39-100.00$ & 79.93 & $30.00-100.00$ \\
\hline$\%$ Previously IST & 6 & 49.23 & $11.11-80.00$ & 9.32 & $0.00-33.33$ \\
\hline
\end{tabular}


Notably, in many instances, the number of studies providing data for the overall sample as identified in Table 3 is not identical to the number of studies providing data for sane and insane subsamples in Table 4. For example, 12 research groups provided sample-level descriptive statistics for race, but only 10 separated these statistics across sane and insane subsamples or provided sufficient raw data to derive descriptive statistics for each subsample. Notably, this was a pattern that continued throughout the meta-analytic process.

Insane and sane samples appeared relatively close in age, sex, employment and marital status, and criminal history. However, there were still notable descriptive differences between the two groups. Sane cases were more often White and had a criminal history. Insane cases more frequently graduated from high school, had a psychiatric history, diagnosed with a psychotic disorder, evaluated for competency to stand trial, and more often found incompetent to stand trial.

\section{Meta-Analysis}

While the following sections will refer to their respective forest plot figures, all metaanalytic findings are detailed in Table 5 for reference. 
Table 5. Meta-Analytic Results.

\begin{tabular}{|c|c|c|c|c|c|c|}
\hline & \multirow[b]{2}{*}{$n$} & \multicolumn{2}{|c|}{ Effect Size } & \multirow{2}{*}{$\frac{\text { Publication Bias }}{\text { Failsafe } N}$} & \multicolumn{2}{|c|}{ Heterogeneity } \\
\hline & & $d$ or $\mathrm{OR}$ & $95 \% \mathrm{CI}$ & & $Q$ & $I^{2}$ \\
\hline \multicolumn{7}{|c|}{ Demographic characteristics } \\
\hline \multicolumn{7}{|l|}{ Age } \\
\hline All studies & 9 & $0.19 *$ & $0.01,0.40$ & 46 & $68.37 * * *$ & 88.30 \\
\hline Referred/evaluated only & 6 & $0.24 * * *$ & $0.12,0.37$ & 77 & $13.10^{*}$ & 61.83 \\
\hline \multicolumn{7}{|l|}{ Sex } \\
\hline All studies & 7 & 0.59 & $0.28,1.23$ & - & $221.15^{* * *}$ & 97.29 \\
\hline Referred/evaluated only & 4 & $1.59 * * *$ & $1.36,1.85$ & 59 & 4.70 & 36.11 \\
\hline \multicolumn{7}{|l|}{ Race } \\
\hline All studies & 10 & 1.36 & $0.95,1.95$ & - & $132.07 * * *$ & 93.19 \\
\hline Referred/evaluated only & 5 & 1.13 & $0.76,1.67$ & - & $63.05 * * *$ & 93.66 \\
\hline \multicolumn{7}{|l|}{ Educational attainment } \\
\hline All studies & 3 & $1.56^{* * *}$ & $1.20,2.03$ & 67 & $12.01 * *$ & 83.34 \\
\hline \multicolumn{7}{|l|}{ Employment status } \\
\hline All studies & 3 & $1.97 * *$ & $1.22,2.87$ & 3 & 1.49 & 0.00 \\
\hline \multicolumn{7}{|l|}{ Marital status } \\
\hline All studies & 4 & 1.21 & $0.80,1.84$ & - & $11.50 * *$ & 73.92 \\
\hline Referred/evaluated only & 2 & 1.18 & $0.49,2.86$ & - & $4.86^{*}$ & 79.43 \\
\hline \multicolumn{7}{|l|}{ Clinical characteristics } \\
\hline \multicolumn{7}{|l|}{ Psychotic Disorder } \\
\hline All studies & 12 & $7.26 * * *$ & $3.86,13.66$ & 3,172 & $390.20 * * *$ & 97.18 \\
\hline Referred/evaluated only & 9 & $12.53 * * *$ & $7.31,21.48$ & 2,967 & $136.71 * * *$ & 94.88 \\
\hline \multicolumn{7}{|l|}{ Treatment history } \\
\hline All studies & 7 & $2.61 * * *$ & $2.14,3.18$ & 480 & $13.76 * * *$ & 56.39 \\
\hline \multicolumn{7}{|l|}{ Legal characteristics } \\
\hline \multicolumn{7}{|l|}{ Criminal history } \\
\hline All studies & 9 & $1.45 * * *$ & $1.18,1.77$ & 94 & $21.89 * *$ & 63.46 \\
\hline Referred/evaluated only & 8 & $1.51 * * *$ & $1.27,1.77$ & 118 & 13.77 & 49.17 \\
\hline \multicolumn{7}{|l|}{ Violent instant offense } \\
\hline All studies & 5 & 1.04 & $0.63,1.73$ & - & $116.38 * * *$ & 96.56 \\
\hline \multicolumn{7}{|l|}{ CST evaluation } \\
\hline All studies & 3 & 2.02 & $0.69,5.91$ & - & 4.42 & 54.72 \\
\hline \multicolumn{7}{|l|}{ Found IST } \\
\hline All studies & 6 & $14.45 * * *$ & $5.51,37.92$ & 125 & $13.67 *$ & 63.41 \\
\hline
\end{tabular}

$* p<.05 . * * p<.01 . * * * p<.001$. 


\section{Demographic characteristics.}

Age. Nine studies provided calculable effect sizes for age (Figure 1).

A

Study name

\begin{tabular}{lrrrrrr} 
& $\begin{array}{c}\text { Std diff } \\
\text { in means }\end{array}$ & $\begin{array}{c}\text { Lower } \\
\text { limit }\end{array}$ & $\begin{array}{r}\text { Upper } \\
\text { limit }\end{array}$ & \multicolumn{2}{c}{ Z-Value } & p-Value \\
Boardman (1996) & 0.377 & 0.061 & 0.692 & 2.340 & 0.019 \\
Johnson et al. (1990) & 0.913 & 0.215 & 1.612 & 2.563 & 0.010 \\
Linhorst \& Tumer (1999) & -0.420 & -0.568 & -0.273 & -5.589 & 0.000 \\
Moskowitz et al. (1999) & 0.174 & -0.293 & 0.640 & 0.730 & 0.466 \\
Packer (1987) & 0.222 & -0.171 & 0.615 & 1.107 & 0.268 \\
Pasewark et al. (1987b) & 0.476 & 0.089 & 0.863 & 2.413 & 0.016 \\
Sreenivasan et al. (1997) & 0.359 & -0.088 & 0.806 & 1.574 & 0.116 \\
Veysey (1993) & 0.121 & 0.071 & 0.171 & 4.754 & 0.000 \\
Warren et al. (2004) & 0.227 & 0.130 & 0.323 & 4.605 & 0.000 \\
& 0.193 & 0.007 & 0.379 & 2.034 & 0.042
\end{tabular}

B

Statistics for each study Std diff in means and $95 \%$ CI

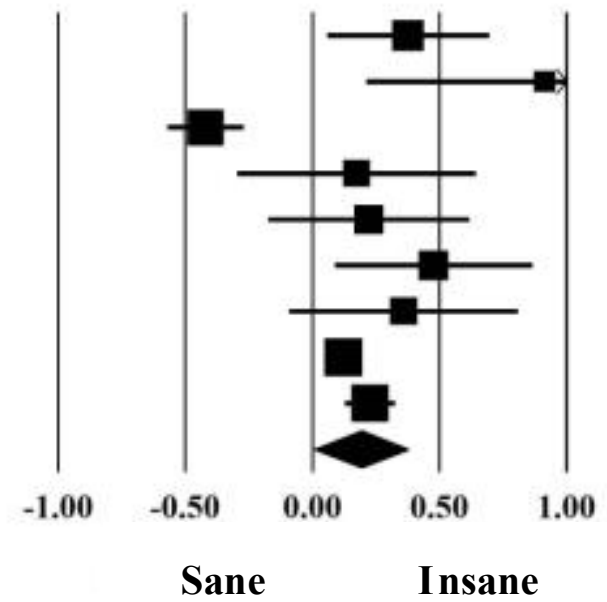

Study name

Boardman (1996)
Johnson et al. (1990)
Packer (1987)
Pasewark et al. (1987b)
Veysey (1993)
Warren et al. (2004)

\begin{tabular}{rrrrrr}
\multicolumn{5}{c}{ Statistics for each study } \\
\cline { 2 - 5 } $\begin{array}{c}\text { Std diff } \\
\text { in means }\end{array}$ & $\begin{array}{c}\text { Lower } \\
\text { limit }\end{array}$ & $\begin{array}{c}\text { Upper } \\
\text { limit }\end{array}$ & Z-Value & p-Value \\
0.377 & 0.061 & 0.692 & 2.340 & 0.019 \\
0.913 & 0.215 & 1.612 & 2.563 & 0.010 \\
0.222 & -0.171 & 0.615 & 1.107 & 0.268 \\
0.476 & 0.089 & 0.863 & 2.413 & 0.016 \\
0.121 & 0.071 & 0.171 & 4.754 & 0.000 \\
0.227 & 0.130 & 0.323 & 4.605 & 0.000 \\
0.244 & 0.120 & 0.368 & 3.852 & 0.000
\end{tabular}

Statistics for each study

Std diff in means and $95 \% \mathrm{CI}$

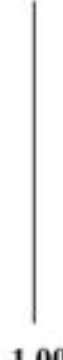

$-1.00$

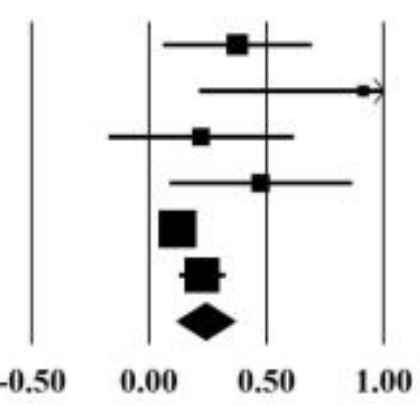

Sane

\section{Insane}

Figure 1. A) Meta-analysis comparing all subgroups according to age. B) Meta-analysis comparing only psycholegal subgroups.

The summary effect indicated a significant age difference between cases classified sane or insane $(d=0.19,95 \% \mathrm{CI}=0.01,0.40, p=.042)$, with older individuals more likely to be 
found insane, although this effect was small. Significant heterogeneity was present $(Q[8]=$ 68.37, $p<.001, I^{2}=88.30$ ). That is, the $Q$ statistic identified that individual effect sizes across these nine studies varied to a significant degree. Furthermore, $I^{2}$ revealed a high level of inconsistency that was attributable to methodological differences, rather than chance alone. Still, the fail-safe $N$ statistic indicated 67 studies with null effects were needed to negate this significant, albeit small, effect. When non-psycholegal cases were dismissed from the analyses, the overall effect was significant, but again small $(n=6, d=0.24,95 \% \mathrm{CI}=0.12,0.37, p<$ .001). Again, older defendants were more often opined insane by evaluators or acquitted insane by the court. Fail-safe $N$ revealed 77 studies with alternative findings could diminish the relationship. Heterogeneity statistics indicated significant variability was still present $(Q[5]=$ 13.10, $\left.p=.020, I^{2}=61.83\right)$. Johnson et al. (1990) was a notable outlier $(d=0.913, p=.010)$, demonstrating a larger effect relative to other studies.

Sex. When considering studies $(n=7)$ that included both males and females, the overall effect for insanity classification was not significant $(\mathrm{OR}=0.59,95 \% \mathrm{CI}: 0.28,1.23, p=.161$; see Figure 2). 
A

\begin{tabular}{lcccrrr} 
Study name & \multicolumn{5}{c}{ Statistics for each study } \\
& $\begin{array}{c}\text { Odds } \\
\text { ratio }\end{array}$ & $\begin{array}{c}\text { Lower } \\
\text { limit }\end{array}$ & $\begin{array}{c}\text { Upper } \\
\text { limit }\end{array}$ & Z-Value & p-Value \\
Boardman (1996) & 2.662 & 1.176 & 6.027 & 2.349 & 0.019 \\
Hays (1999) & 1.393 & 0.726 & 2.675 & 0.996 & 0.319 \\
Linhorst \& Turner (1999) & 0.195 & 0.131 & 0.291 & -8.029 & 0.000 \\
Moskowitz et al. (1999) & 0.004 & 0.001 & 0.012 & -10.261 & 0.000 \\
Powell (1998) & 1.470 & 1.197 & 1.805 & 3.674 & 0.000 \\
Veysey (1993) & 1.749 & 1.498 & 2.042 & 7.073 & 0.000 \\
Warren et al. (2004) & 1.378 & 1.064 & 1.785 & 2.428 & 0.015 \\
& 0.594 & 0.286 & 1.231 & -1.402 & 0.161
\end{tabular}

Odds ratio and $95 \% \mathrm{CI}$

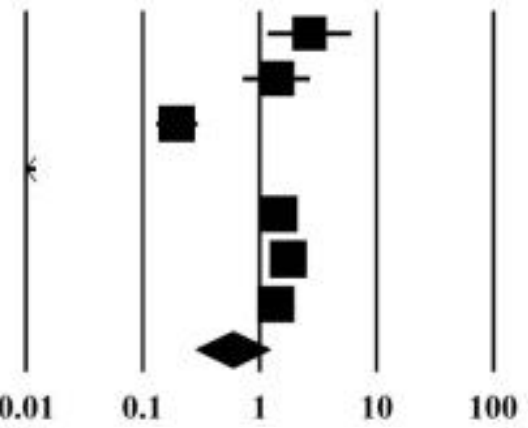

Sane Insane

B

Study name

Statistics for each study

Odds ratio and $95 \% \mathrm{CI}$

$\begin{array}{lccccrr} & \begin{array}{c}\text { Odds } \\ \text { ratio }\end{array} & \begin{array}{c}\text { Lower } \\ \text { limit }\end{array} & \begin{array}{c}\text { Upper } \\ \text { limit }\end{array} & \text { Z-Value } & \text { p-Value } \\ \text { Boardman (1996) } & 2.662 & 1.176 & 6.027 & 2.349 & 0.019 \\ \text { Powell (1998) } & 1.470 & 1.197 & 1.805 & 3.674 & 0.000 \\ \text { Veysey (1993) } & 1.749 & 1.498 & 2.042 & 7.073 & 0.000 \\ \text { Warren et al. (2004) } & 1.378 & 1.064 & 1.785 & 2.428 & 0.015 \\ & 1.587 & 1.361 & 1.852 & 5.877 & 0.000\end{array}$

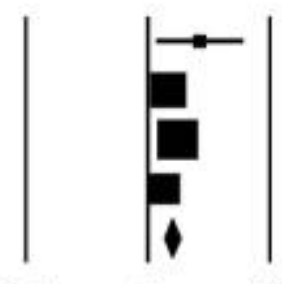

$\begin{array}{llll}0.1 & 1 & 10 & 100\end{array}$

Sane Insane

Figure 2. A) Meta-analysis comparing all subgroups according to sex. B) Meta-analysis comparing only psycholegal subgroups.

Marked heterogeneity was identified $\left(Q[6]=221.15, p<.001 ; I^{2}=97.29\right)$. It was evident the non-psycholegal cases negatively impacted the summary effect. With non-psycholegal cases removed from the analyses, it was significant $(\mathrm{OR}=1.59,95 \% \mathrm{CI}: 1.36,1.85, p<.001$, with fail-safe $N=59$ ). Female cases had nearly 1.6 the odds of being classified insane among referred or trial defendants. No significant heterogeneity was identified $\left(Q[3]=4.70, p=.196, I^{2}=\right.$ 
36.11).

Race. When looking at race data $(n=10)$, the overall effect was not significant $(\mathrm{OR}=$ $1.36,95 \% \mathrm{CI}=0.95,1.95, p=.098$; Figure 3 )

\section{A}

Study name

$\begin{array}{lrrrrr} & \begin{array}{c}\text { Odds } \\ \text { ratio }\end{array} & \begin{array}{c}\text { Lower } \\ \text { limit }\end{array} & \begin{array}{c}\text { Upper } \\ \text { limit }\end{array} & \begin{array}{r}\text { Z-Value } \\ \text { p-Value }\end{array} \\ \text { Boardman (1996) } & 1.072 & 0.548 & 2.097 & 0.203 & 0.839 \\ \text { Boehnert (1989) } & 1.784 & 0.616 & 5.169 & 1.067 & 0.286 \\ \text { Hays (1999) } & 0.384 & 0.238 & 0.618 & -3.937 & 0.000 \\ \text { Heilbrun \& Heilbrun (1989) } & 2.153 & 1.178 & 3.936 & 2.493 & 0.013 \\ \text { Linhorst \& Turner (1999) } & 3.096 & 2.219 & 4.318 & 6.654 & 0.000 \\ \text { Moskowitz et al. (1999) } & 6.042 & 2.016 & 18.108 & 3.212 & 0.001 \\ \text { Powell (1998) } & 1.752 & 1.518 & 2.022 & 7.680 & 0.000 \\ \text { Sreenivasan et al. (1997) } & 1.348 & 0.526 & 3.454 & 0.623 & 0.533 \\ \text { Veysey (1993) } & 0.941 & 0.851 & 1.039 & -1.206 & 0.228 \\ \text { Warren et al. (2004) } & 0.750 & 0.605 & 0.931 & -2.616 & 0.009 \\ & 1.359 & 0.945 & 1.954 & 1.654 & 0.098\end{array}$

Statistics for each study

Odds ratio and $95 \% \mathrm{CI}$

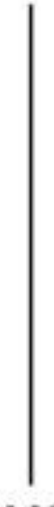

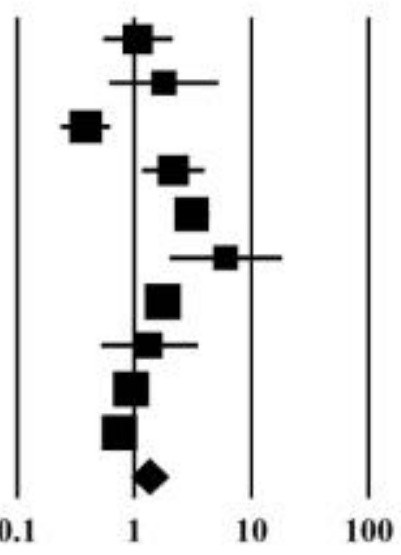

Sane

Insane

B

Study name

$\begin{array}{lcccrrr} & \begin{array}{r}\text { Odds } \\ \text { ratio }\end{array} & \begin{array}{c}\text { Lower } \\ \text { limit }\end{array} & \begin{array}{c}\text { Upper } \\ \text { limit }\end{array} & \text { Z-Value } & \text { p-Value } \\ \text { Boardman (1996) } & 1.072 & 0.548 & 2.097 & 0.203 & 0.839 \\ \text { Boehnert (1989) } & 1.784 & 0.616 & 5.169 & 1.067 & 0.286 \\ \text { Powell (1998) } & 1.752 & 1.518 & 2.022 & 7.680 & 0.000 \\ \text { Veysey (1993) } & 0.941 & 0.851 & 1.039 & -1.206 & 0.228 \\ \text { Warren et al. (2004) } & 0.750 & 0.605 & 0.931 & -2.616 & 0.009 \\ & 1.127 & 0.759 & 1.674 & 0.594 & 0.553\end{array}$

Odds ratio and $95 \% \mathrm{CI}$

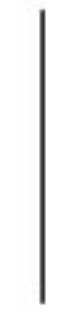

0.01

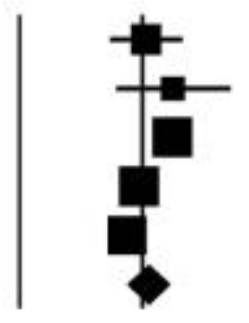

0.1

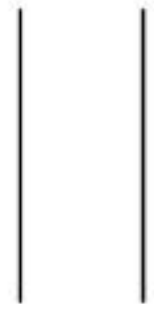

10100

Sane Insane

Figure 3. A) Meta-analysis comparing all subgroups according to race. B) Meta-analysis comparing only psycholegal subgroups. 
There was high heterogeneity $\left(Q[9]=132.07, p<.001 ; I^{2}=93.19\right)$ across studies. Again, nonpsycholegal groups, particularly Hays (1999), Linhorst and Turner (1999), and Moskowitz et al. (1999) appeared to influence the overall result. However, removing these comparison groups from the analyses did not substantially change the overall effect for race on insanity outcomes $(\mathrm{OR}=1.13,95 \% \mathrm{CI}=0.76,1.67, p=.553)$, and heterogeneity was still significant $(Q[4]=$ 63.05, $\left.p<.001, I^{2}=93.66\right)$. Only Powell (1998) was significant in finding that Non-Whites were more likely to be found insane. Warren et al. (2004) was the only study to find that Non-Whites were less likely to be opined insane to a significant degree.

Education. Only three studies — all comprised of psycholegal groups — were available for education comparisons (Figure 4).

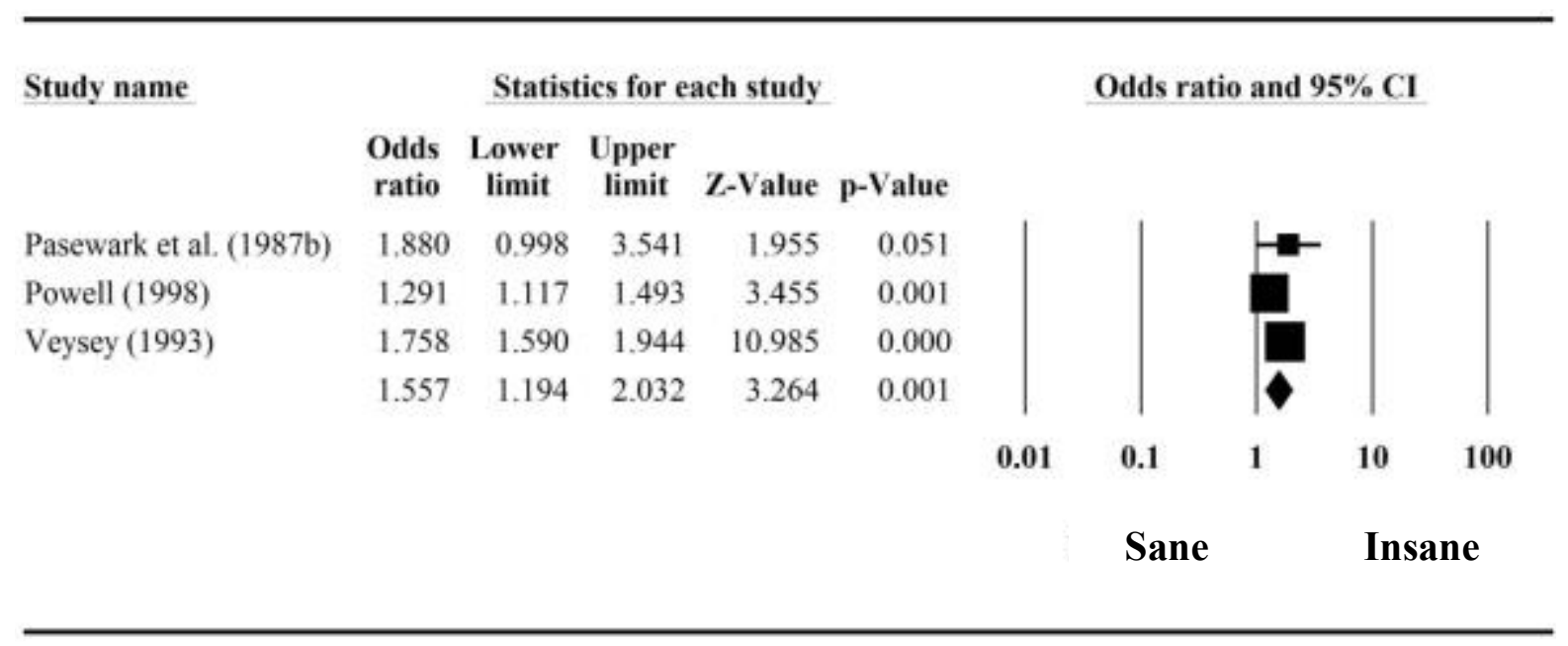

Figure 4. Meta-analysis comparing all psycholegal subgroups according to completion of high school.

The finding was significant $(\mathrm{OR}=1.56,95 \% \mathrm{CI}: 1.20,2.03, p<.001)$, and can be interpreted as when defendants graduated high school, the odds they would be opined insane had a 1.5 increase. The fail-safe $N$ indicated 67 studies were needed to render a trivial finding. Marked heterogeneity was identified $\left(Q[2]=12.01, p=.002, I^{2}=83.34\right)$.

Employment. In Figure 5 we see that three studies, all psycholegal, provided calculable 
effect sizes for employment status.

\begin{tabular}{|c|c|c|c|c|c|c|c|c|c|}
\hline \multirow[t]{2}{*}{ Study name } & \multicolumn{5}{|c|}{ Statistics for each study } & \multicolumn{4}{|c|}{ Odds ratio and $95 \% \mathrm{CI}$} \\
\hline & $\begin{array}{c}\text { Odds } \\
\text { ratio }\end{array}$ & $\begin{array}{c}\text { Lower } \\
\text { limit }\end{array}$ & $\begin{array}{c}\text { Upper } \\
\text { limit }\end{array}$ & $\mathrm{Z}$-Value & p-Value & & & & \\
\hline Boardman (1996) & 3.058 & 1.161 & 8.058 & 2.262 & 0.024 & 1 & & - & 1 \\
\hline Boehnert (1989) & 1.000 & 0.131 & 7.605 & 0.000 & 1.000 & & & & \\
\hline \multirow[t]{4}{*}{ Pasewark et al. (1987a) } & 1,705 & 1.042 & 2.791 & 2.124 & 0.034 & & & & \\
\hline & 1.867 & 1.216 & 2.868 & 2.853 & 0.004 & & & & \\
\hline & & & & & & 0.01 & 0.1 & 10 & 100 \\
\hline & & & & & & & Sane & Insa & \\
\hline
\end{tabular}

Figure 5. Meta-analysis comparing all psycholegal groups according to employment status.

Results revealed unemployed cases had 2 times the odds of being opined insane $(\mathrm{OR}=1.87$, $95 \% \mathrm{CI}=1.22,2.87, p=.004)$. This finding was not particularly robust: fail-safe $N$ suggested 3 studies with null findings would need to be identified to negate its significance. Notably, Boehnert (1989) found a precisely neutral effect for employment. Although it was not matched for employment, the same number of cases within sane and insane groups was employed in Boehnert's study. Aside from this, the other two studies in this analysis showed relatively consistent effects. The $Q$ statistic was not significant $\left(Q[2]=1.49 p=0.475, I^{2}=0.00\right)$.

Marital status. Four studies provided calculable effect sizes for marital status. The overall effect was not significant $(\mathrm{OR}=1.21,95 \% \mathrm{CI}: 0.80,1.84, p=.370$; Figure 6$)$. 
A

Study name

$\begin{array}{lcccccc} & \begin{array}{c}\text { Odds } \\ \text { ratio }\end{array} & \begin{array}{c}\text { Lower } \\ \text { limit }\end{array} & \begin{array}{c}\text { Upper } \\ \text { limit }\end{array} & \text { Z-Value } & \text { p-Value } \\ \text { Boardman (1996) } & 0.679 & 0.302 & 1.525 & -0.938 & 0.348 \\ \text { Linhorst \& Turner (1999) } & 1.085 & 0.802 & 1.468 & 0.532 & 0.595 \\ \text { Moskowitz et al. (1999) } & 1.031 & 0.194 & 5.492 & 0.036 & 0.971 \\ \text { Veysey (1993) } & 1.710 & 1.489 & 1.963 & 7.618 & 0.000 \\ & 1.211 & 0.796 & 1.842 & 0.896 & 0.370\end{array}$

Odds ratio and $95 \% \mathrm{Cl}$

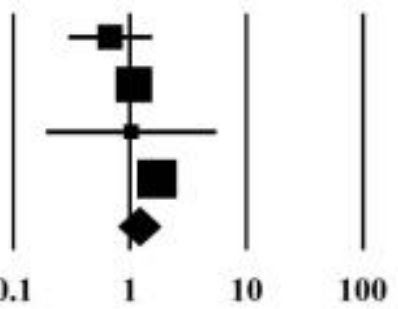

Sane

Insane

B

Study name

\begin{tabular}{lcccrrr} 
& $\begin{array}{c}\text { Odds } \\
\text { ratio }\end{array}$ & $\begin{array}{c}\text { Lower } \\
\text { limit }\end{array}$ & $\begin{array}{c}\text { Upper } \\
\text { limit }\end{array}$ & \multicolumn{2}{c}{ Z-Value } & p-Value \\
Boardman (1996) & 0.679 & 0.302 & 1.525 & -0.938 & 0.348 \\
Veysey (1993) & 1.710 & 1.489 & 1.963 & 7.618 & 0.000 \\
& 1.178 & 0.485 & 2.864 & 0.362 & 0.717
\end{tabular}

Statistics for each study

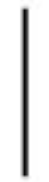

0.01

\section{Odds ratio and $95 \%$ CI}

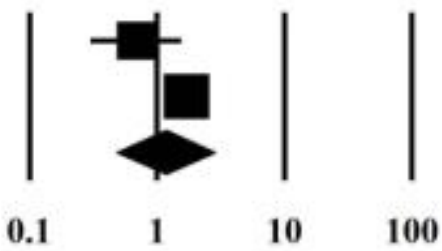

Sane Insane

Figure 6. A) Meta-analysis comparing all subgroups according to marital status. B) Metaanalysis comparing only psycholegal subgroups.

Significant heterogeneity was identified $\left(Q[3]=11.50, p=0.009, I^{2}=73.92\right)$. The effect did not change in its significance once non-psycholegal groups were removed $(\mathrm{OR}=1.18,95 \% \mathrm{CI}=$ $0.49,2.86, p=0.717)$. The $Q([1]=4.86, p=0.027)$ and $I^{2}(79.43 \%)$ statistics again revealed significant heterogeneity. 


\section{Clinical characteristics.}

Treatment history. Eight studies provided complete data regarding treatment history

(Figure 7).

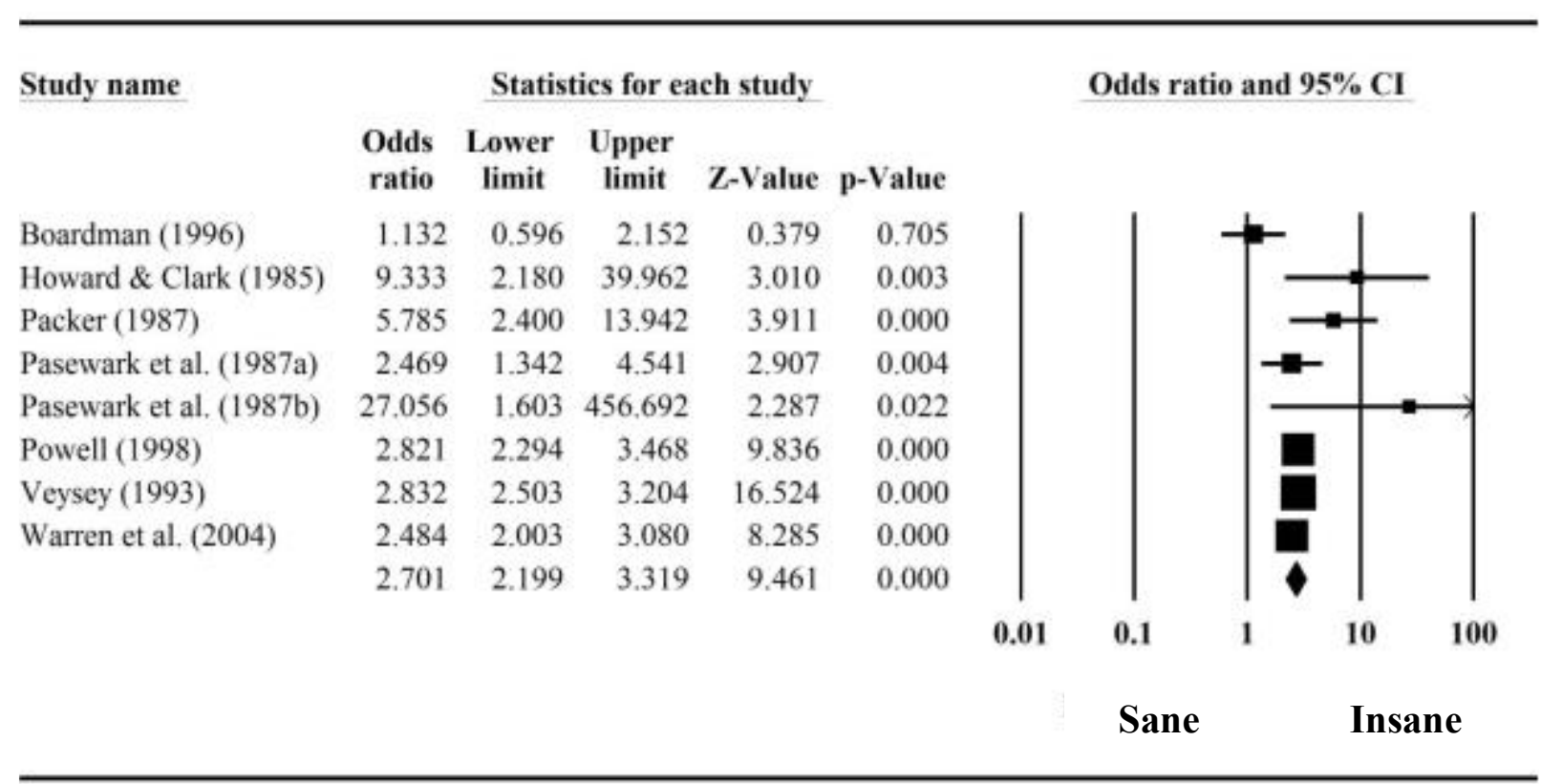

Figure 7. Meta-analysis comparing all psycholegal groups according to treatment history.

Results indicated cases with some form of past mental health treatment increased odds of being classified insane by $2.5(\mathrm{OR}=2.70,95 \% \mathrm{CI}=2.20,3.32, p<.001)$. The fail-safe $N$ found that 571 studies with opposite or null findings would need to be revealed to render this finding nonsignificant. Moderate heterogeneity was found $\left(Q[7]=16.55, p=.021, I^{2}=57.71\right)$. Pasewark et al. (1987b) had a large effect, accompanied by a large confidence interval. Boardman (1996) was the only study that did not find defendants with a treatment history were more likely to be found insane. No alternative comparison groups were considered in this analysis. 
Diagnosis. Figure 8 presents the 12 studies that provided calculable effect sizes for diagnosis.

A

Study name

\begin{tabular}{lrrrrr} 
& $\begin{array}{r}\text { Odds } \\
\text { ratio }\end{array}$ & $\begin{array}{c}\text { Lower } \\
\text { limit }\end{array}$ & $\begin{array}{c}\text { Upper } \\
\text { limit }\end{array}$ & \multicolumn{2}{c}{ Z-Value p-Value } \\
Boardman (1996) & 12.132 & 5.988 & 24.581 & 6.928 & 0.000 \\
Hays (1999) & 0.788 & 0.461 & 1.350 & -0.867 & 0.386 \\
Howard \& Clark (1985) & 361.000 & 21.011 & 6202.406 & 4.059 & 0.000 \\
Johnson et al. (1990) & 44.811 & 2.516 & 798.185 & 2.588 & 0.010 \\
Linhorst \& Turner (1999) & 0.997 & 0.732 & 1.359 & -0.016 & 0.987 \\
Moskowitz et al. (1999) & 1.733 & 0.641 & 4.686 & 1.084 & 0.278 \\
Nestor \& Haycock (1997) 168.000 & 9.458 & 2983.989 & 3.491 & 0.000 \\
Packer (1987) & 27.984 & 9.538 & 82.108 & 6.066 & 0.000 \\
Pasewark et al. (1987b) & 15.636 & 6.139 & 39.826 & 5.764 & 0.000 \\
Powell (1998) & 16.543 & 13.925 & 19.654 & 31.920 & 0.000 \\
Veysey (1993) & 8.305 & 7.410 & 9.309 & 36.361 & 0.000 \\
Warren et al. (2004) & 3.790 & 3.110 & 4.618 & 13.214 & 0.000 \\
& 7.256 & 3.855 & 13.658 & 6.141 & 0.000
\end{tabular}

Statistics for each study

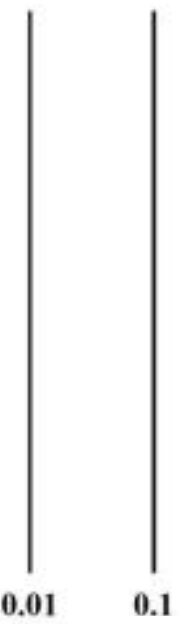

Sane
Odds ratio and $95 \% \mathrm{CI}$

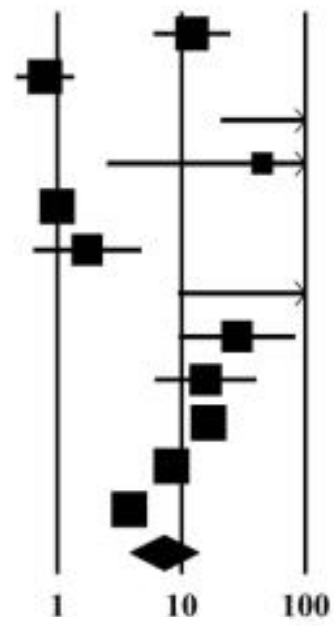

Insane

B

Study name

\begin{tabular}{lrrrrrr} 
& $\begin{array}{c}\text { Odds } \\
\text { ratio }\end{array}$ & $\begin{array}{c}\text { Lower } \\
\text { limit }\end{array}$ & $\begin{array}{r}\text { Upper } \\
\text { limit }\end{array}$ & \multicolumn{2}{c}{ Z-Value p-Value } \\
Boardman (1996) & 12.132 & 5.988 & 24.581 & 6.928 & 0.000 \\
Howard \& Clark (1985) & 361.000 & 21.011 & 6202.406 & 4.059 & 0.000 \\
Johnson et al. (1990) & 44.811 & 2.516 & 798.185 & 2.588 & 0.010 \\
Packer (1987) & 27.984 & 9.538 & 82.108 & 6.066 & 0.000 \\
Pasewark et al. (1987b) & 15.636 & 6.139 & 39.826 & 5.764 & 0.000 \\
Powell (1998) & 16.543 & 13.925 & 19.654 & 31.920 & 0.000 \\
Veysey (1993) & 8.305 & 7.410 & 9.309 & 36.361 & 0.000 \\
Warren et al. (2004) & 3.790 & 3.110 & 4.618 & 13.214 & 0.000 \\
& 12.527 & 7.305 & 21.482 & 9.186 & 0.000
\end{tabular}

Statistics for each study

Odds ratio and $95 \% \mathrm{CI}$

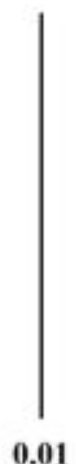

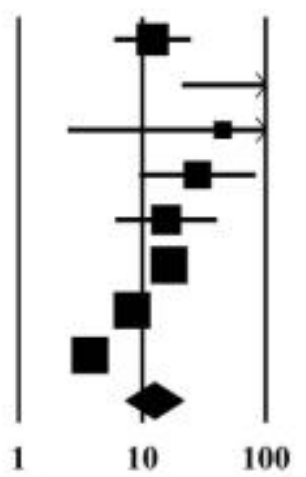

Insane 
Results revealed individuals diagnosed psychotic had roughly 7 times the odds of being classified insane $(\mathrm{OR}=7.26,95 \% \mathrm{CI}=3.86,13.66, p<.001)$. This was a robust finding: the failsafe $N$ indicated 3,172 null findings would be needed to negate significance. Significant heterogeneity was found $\left.Q[11]=390.20, p<.001, I^{2}=97.18\right)$. Indeed, non-psycholegal groups appeared to reduce the summary effect. Conducting analyses without these groups increased the OR to $12.53(95 \% \mathrm{CI}=7.3121 .48, p<.001)$. Stated differently, examining only psycholegal groups increased the OR by five fold. This was another robust finding (fail-safe $N=2,967$ ), although high heterogeneity was still identified $\left(Q[8]=136.71, p<.001, I^{2}=94.88\right)$.

\section{Legal characteristics.}

Criminal history. Cases without a criminal history had about 1.5 the odds to be classified as insane $(n=9 ; \mathrm{OR}=1.45,95 \% \mathrm{CI}=1.18,1.77, p<.001 ;$ Figure 9). 
A

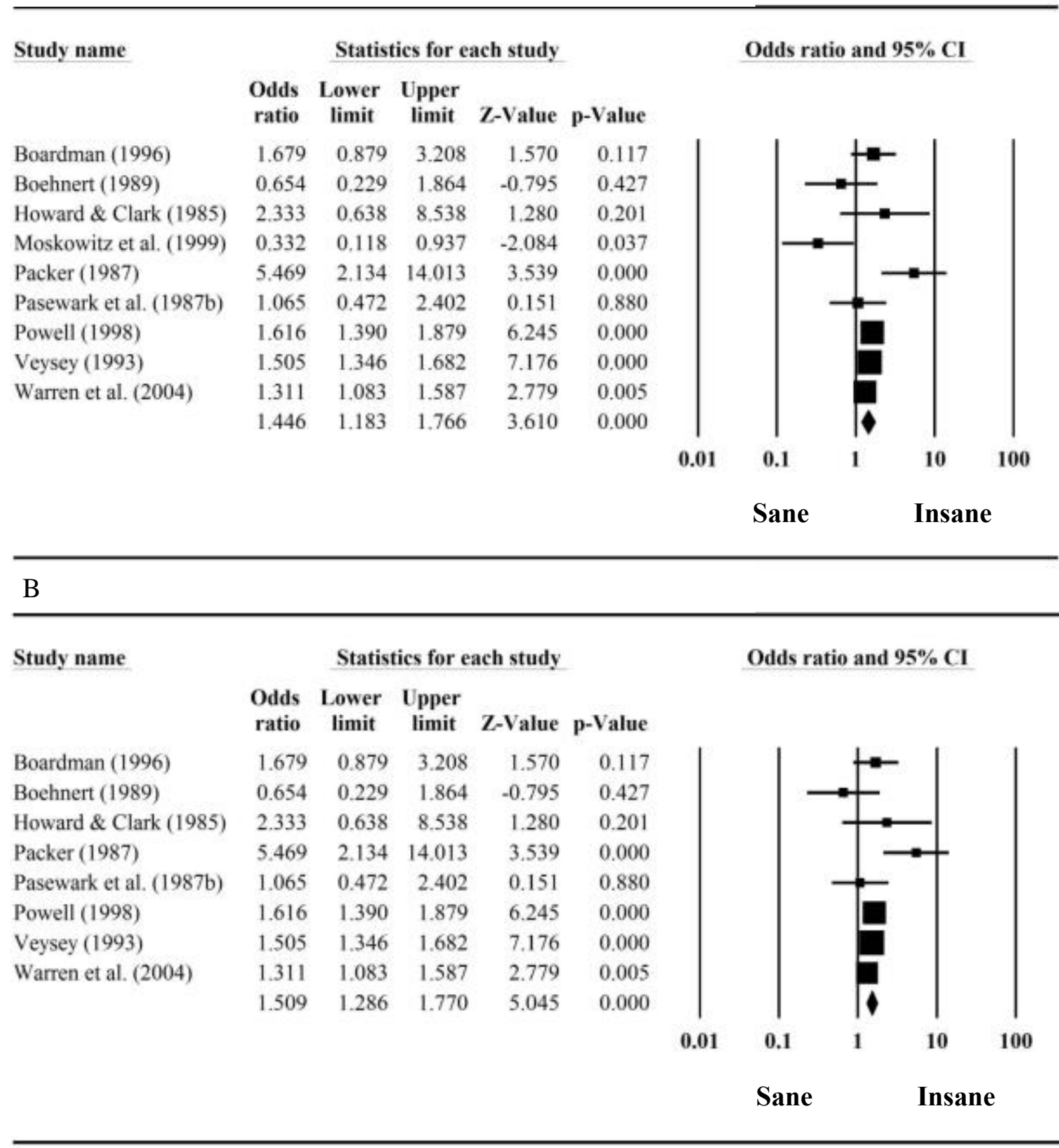

Odds ratio and $95 \%$ CI

Figure 9. A) Meta-analysis comparing all subgroups according to criminal history. B) Meta-analysis comparing only psycholegal subgroups.

As such, those with a criminal history had about one-third less odds to be found insane. This was a robust finding, as the fail-safe $N$ indicated 94 studies would need to be located with null or opposite findings to negate this result. The $Q$ statistic revealed significant heterogeneity $(Q[8]=$ 
21.89, $\left.p=.005, I^{2}=63.46\right)$. After removing non-psycholegal groups, the summary effect was virtually the same $(\mathrm{OR}=1.5195 \% \mathrm{CI}=1.27,1.77, p<.001)$, while fail-safe $N(118)$ indicated an even more robust finding. There was a trend toward significant heterogeneity, although it did not meet statistical significance $\left(Q[7]=13.77, p=.055, I^{2}=49.17\right)$.

Violent instant offense. The five studies providing data to calculate ORs for cases with and without violent charges are depicted in Figure 10.

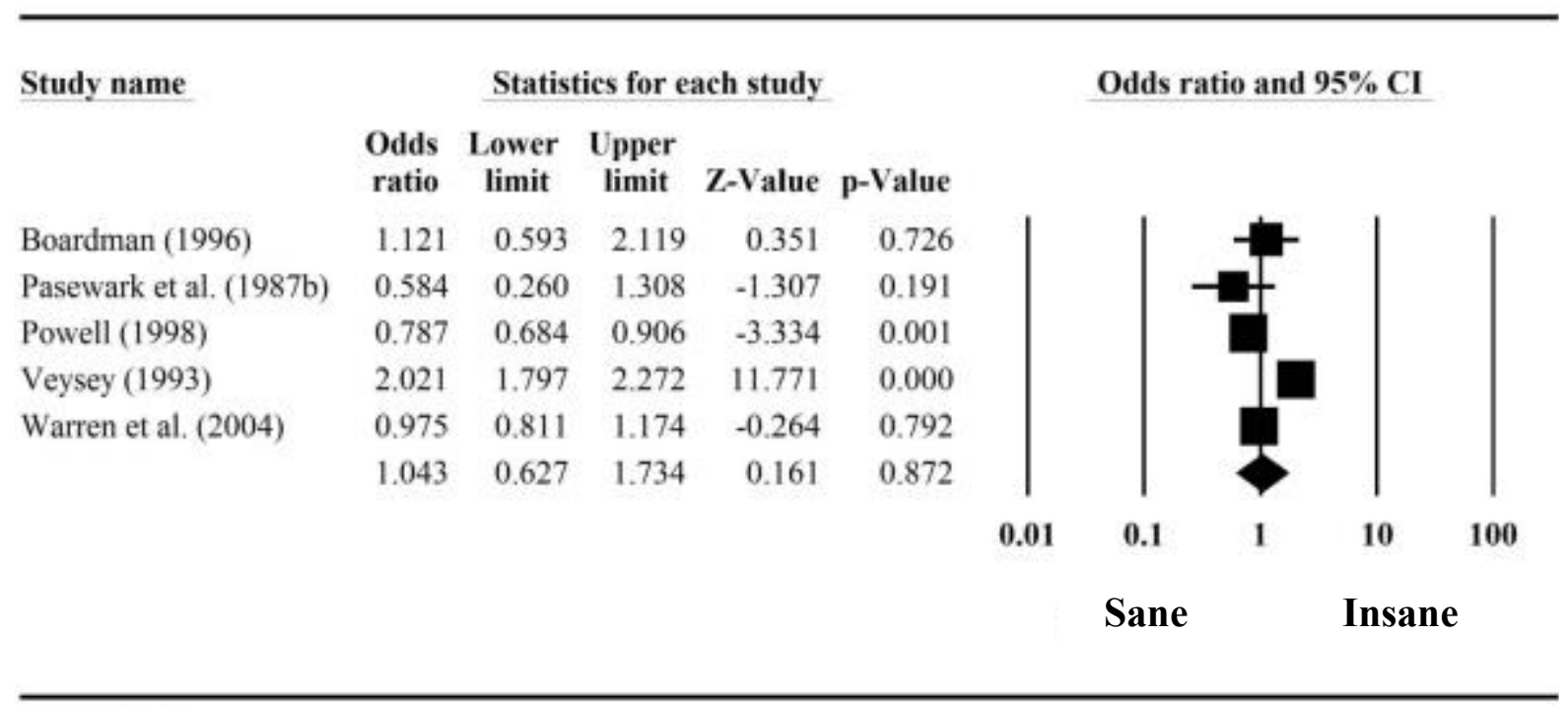

Figure 10. A) Meta-analysis comparing all psycholegal groups according to offense type.

There was no significant summary effect identified: $\mathrm{OR}=1.04,95 \% \mathrm{CI}=0.63,1.73, p=.872$. Marked heterogeneity was found: $Q(4)=116.38, p<.001, I^{2}=96.56$. No sensitivity analyses were required, as this variable was not recorded for non-psycholegal comparison groups.

Competency evaluation history. There were three studies in which competency evaluations varied across psycholegal subgroups (Figure 11). 


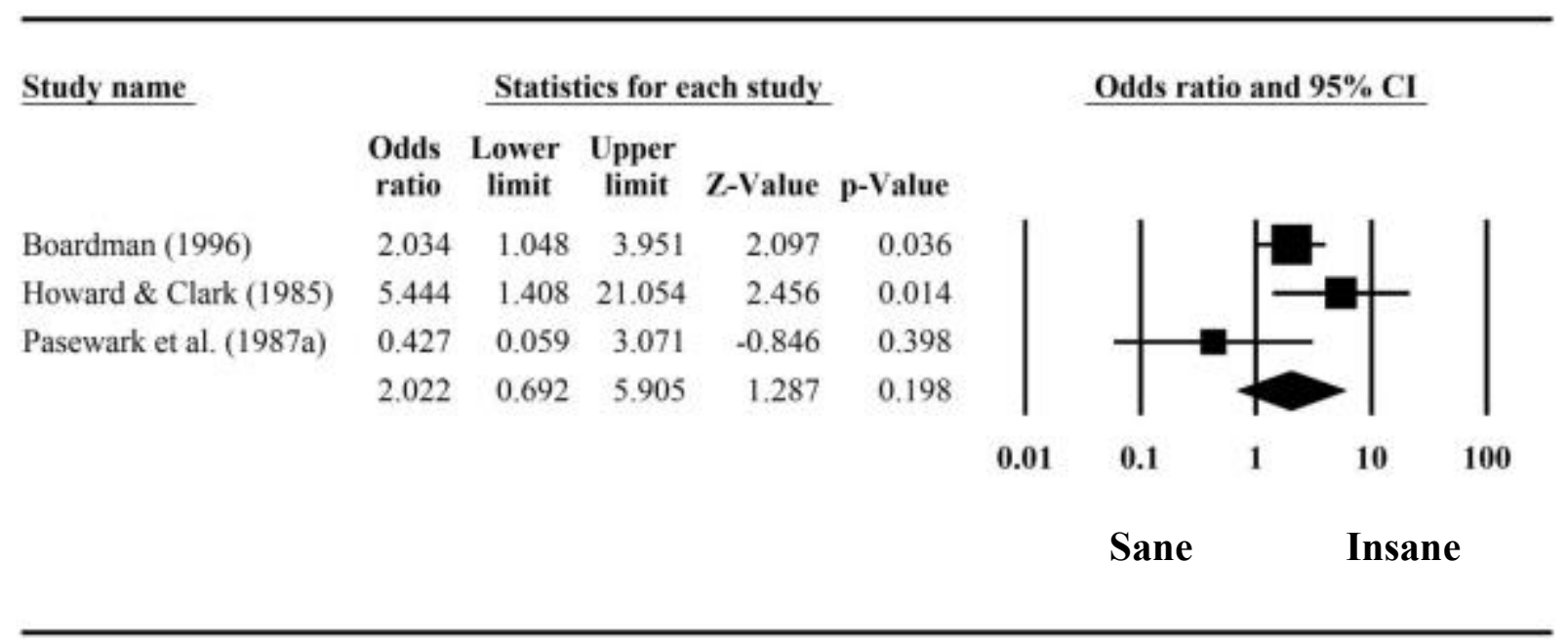

Figure 11. A) Meta-analysis comparing psycholegal subgroups according to CST referrals.

However, the summary effect was not significant $(\mathrm{OR}=2.70,95 \% \mathrm{CI}=0.69,5.91, p=.198)$.

There was moderate heterogeneity across the studies $\left(Q[2]=4.42, p=.110, I^{2}=54.72\right)$.

Incompetency history. Figure 12 shows that either evaluators' or the courts' opinions on defendants' competency to stand trial was provided in six studies.

\begin{tabular}{|c|c|c|c|c|c|c|c|c|}
\hline \multirow[t]{2}{*}{ Study name } & \multicolumn{5}{|c|}{ Statistics for each study } & & \multicolumn{2}{|c|}{ Odds ratio and $95 \% \mathrm{CI}$} \\
\hline & $\begin{array}{c}\text { Odds } \\
\text { ratio }\end{array}$ & $\begin{array}{c}\text { Lower } \\
\text { limit }\end{array}$ & $\begin{array}{c}\text { Upper } \\
\text { limit }\end{array}$ & Z-Value & p-Value & & & \\
\hline Boardman (1996) & 5.217 & 1.778 & 15.314 & 3.007 & 0.003 & & & \\
\hline Boehnert (1989) & 8.000 & 2.475 & 25.860 & 3.474 & 0.001 & & & \\
\hline Howard \& Clark (1985) & 17.000 & 0.803 & 359.805 & 1.819 & 0.069 & & & \\
\hline Johnson et al. (1990) & 10.750 & 0.613 & 188.637 & 1.625 & 0.104 & & & \\
\hline Packer (1987) & 13.054 & 4.823 & 35.327 & 5.058 & 0.000 & & & \\
\hline \multirow[t]{4}{*}{ Pasewark et al. (1987a) } & 92.571 & 27.844 & 307.769 & 7.387 & 0.000 & & & \\
\hline & 14.448 & 5.505 & 37.922 & 5.424 & 0.000 & & & \\
\hline & & & & & & 0.01 & 0.1 & 10 \\
\hline & & & & & & & Sane & Insane \\
\hline
\end{tabular}

Figure 12. A) Meta-analysis comparing psycholegal groups according to incompetence to stand trial history.

Results indicated defendants opined incompetent by evaluations or found incompetent by the 
court had 15 times the odds of an insane classification $(\mathrm{OR}=14.45,95 \% \mathrm{CI}=5.51,37.92, p<$ $.001)$. Moderate heterogeneity was identified within the sample $\left(Q[5]=13.67, p=.018, I^{2}=\right.$ 63.41). This was a robust finding (fail-safe $N=125)$.

\section{Study Space Results}

Table 6 provides study space findings, with demographic, clinical, legal variables parsed out according to insanity criteria (ALI or M'Naghten variants) and opinion source (evaluator or court).

Table 6. Study Space Analysis: Defendant Characteristics by CR Outcomes (N = 7).

\begin{tabular}{|c|c|c|c|c|}
\hline & \multicolumn{4}{|c|}{ CR Outcome } \\
\hline & \multicolumn{2}{|c|}{ ALI or variant } & \multicolumn{2}{|c|}{ M'Naghten or variant } \\
\hline & Evaluator & Court & Evaluator & Court \\
\hline & $n(\%)$ & $n(\%)$ & $n(\%)$ & $n(\%)$ \\
\hline \multicolumn{5}{|l|}{ Demographic Characteristics } \\
\hline Age & $0(0.00)$ & $1(25.00)$ & $2(50.00)$ & $1(25.00)$ \\
\hline Sex & $0(0.00)$ & $0(\mathbf{0 . 0 0})$ & $1(100.00)$ & $0(\mathbf{0 . 0 0})$ \\
\hline Race & $0(0.00)$ & $0(\mathbf{0 . 0 0})$ & $1(50.00)$ & $1(50.00)$ \\
\hline Education & $0(0.00)$ & $0(\mathbf{0 . 0 0})$ & $0(\mathbf{0 . 0 0})$ & $1(100.00)$ \\
\hline Employment & $0(0.00)$ & $1(50.00)$ & $0(\mathbf{0 . 0 0})$ & $1(50.00)$ \\
\hline Marital status & $0(0.00)$ & $0(\mathbf{0 . 0 0 )}$ & $0(0.00)$ & $0(\mathbf{0 . 0 0})$ \\
\hline \multicolumn{5}{|l|}{ Clinical Characteristics } \\
\hline Treatment history & $0(\mathbf{0 . 0 0})$ & $3(60.00)$ & $1(20.00)$ & $1(20.00)$ \\
\hline Diagnosis & $0(\mathbf{0 . 0 0})$ & $2(40.00)$ & $2(40.00)$ & $1(20.00)$ \\
\hline \multicolumn{5}{|l|}{ Legal Characteristics } \\
\hline Criminal history & $0(0.00)$ & $2(40.00)$ & $1(20.00)$ & $2(40.00)$ \\
\hline Violent offense & $0(0.00)$ & $0(\mathbf{0 . 0 0})$ & $1(50.00)$ & $1(50.00)$ \\
\hline Competence evaluation history & $0(0.00)$ & $2(66.67)$ & $0(0.00)$ & $1(33.33)$ \\
\hline Previous incompetence finding & $0(0.00)$ & $3(60.00)$ & $1(20.00)$ & $1(20.00)$ \\
\hline
\end{tabular}


Although 16 reports met criteria for the meta-analysis, only seven studies subsequently met criteria for the study space: dissertations and reports utilizing non-psycholegal comparison groups were removed as these study characteristics did not align with admissibility and methodological standards recommended by Malpass et al. (2008). With these studies excluded, all studies used ALI $(n=3)$ or M'Naghten $(n=4)$ criterion. Of note, reports incorporating subsamples with shared characteristics (e.g., sex, nature of offense) were not counted among study space frequencies for that variable. Bolded cells in Table 6 indicate relatively understudied variable combinations. Notably, no studies examined variable relationships according to ALI/evaluator opinions.

\section{Demographic Characteristics}

In looking at demographic characteristics, only four studies examined age as a predictor of CR outcomes. Half were in the context of M'Naghten/evaluator opinions, and next divided evenly among M'Naghten/court and ALI/court opinions. Only one study examined sex as a predictor, as eligible studies typically considered same-sex samples. This particular analysis was under evaluators' M'Naghten opinions. Analyses of race took place in M'Naghten/evaluator and M'Naghten/court analyses. Education was only studied according to the courts' M'Naghten opinions. Employment status was equally examined across ALI and M'Naghten court opinions. None of the eligible studies considered marital status in their analyses.

\section{Clinical Characteristics}

Both clinical characteristics were the most frequently studied variables found in the study space. Treatment history was studied in all contexts aside from evaluators' ALI/evaluator opinions and was concentrated for ALI/court opinions. Recall that treatment history was operationalized by numerous means across the eligible studies, and so the definition of this 
variable is not uniformly distributed here. Diagnosis was better dispersed across CR outcome possibilities, but like treatment history, it was not assessed in eligible ALI/evaluator opinion studies.

\section{Legal Characteristics}

Turning to criminal characteristics, criminal history was a commonly studied variable, and was dispersed almost evenly across potential CR outcomes with the exception of ALI/evaluator opinions. It is important to keep in mind, however, that criminal history was measured using various methods, and so operationalization of this variable is inconsistent across studies. Violent nature of the offense was present in only M'Naghten evaluator and court opinions. Competence history was studied, most frequently in ALI/court contexts, and never in ALI/evaluator contexts.

\section{Discussion}

This is the first project to empirically consolidate CR research through meta-analysis and the first to systematically identify areas for future CR study via a study space. Consistent with expectations, I found that indicators of severe mental illness were robust predictors of insanity outcomes. Although several significant meta-analytic summary effects were identified, significant heterogeneity in findings demonstrated that such "broad strokes" analyses masked important differences across CR study methodology. The study space revealed a dearth of CR research once accounting for the many methods of measuring CR constructs. Taken together, the project moved us closer to the goals of understanding what we know and what we need to know.

\section{Meta-Analytic Findings: Predicting Insanity Outcomes}

Study-level characteristics. A primary goal of this project was to better understand how methodological considerations might impact CR research findings. Review of study-level 
characteristics made clear that researchers take a range of approaches in addressing this area of the literature. Very few studies utilized the same methodology. In fact, only three studies were similar in their comparison groups and legal test criteria. This is not particularly surprising, as the construct of CR itself varies across jurisdictions. Further, defendants who raise the insanity defense are few and far between, and CR researchers, who typically utilize archival rather than prospective data, must work with what is available to them.

Insanity base rates. Past research indicates that evaluators opine approximately $10 \%$ of defendants insane, whereas the court acquits approximately $25 \%$ of defendants who plea insanity at trial (Cochrane et al., 2001; Johnson et al., 1990; McGinley \& Pasewark, 1989; Steadman et al., 1993; Warren et al., 1997; Warren et al., 2004). The hypothesized base rates of $10 \%$ of $25 \%$, respectively, were supported. Thus, there was a notable difference between evaluators' and the courts' insanity opinion base rates, with the average insanity base rate for defendants acquitted insane at trial was almost twice that of defendants opined insane by evaluators. This finding may at first seem counterintuitive. One might expect that evaluators, who presumably have a more nuanced understanding of mental disorders and their potential impact on psycholegal abilities, would be more inclined to opine defendants insane. With further thought, though, it seems the pattern of findings aligns with the trajectory of defendants moving through the CR process.

Attorneys frequently make CR evaluation referrals not only when they truly doubt defendants' criminal responsibility, but also when they are in search of mitigating circumstances for plea-bargaining or to delay proceedings (Pasewark \& Craig, 1980). Therefore, the pool of defendants referred for CR evaluations may not accurately reflect those genuinely suspected of CR psycholegal impairment. Defendants in this group are at the first stage of the CR "filtering process" and it would be expected the vast majority would be opined sane by evaluators. 
It is likely that information attorneys glean from evaluations- - based on evaluators' analyses of defendants' mental health history and psycholegal impairment at the time of the offense - guides trial strategy and creates downstream implications. Defendants opined sane by evaluators could be more inclined to seek plea bargains or proceed with alternate trial strategies. Conversely, the pool of defendants opined insane by evaluators and who subsequently raise the defense at trial should likely comprise more of a "true" insane group. It follows that a larger percentage of these defendants would be more often acquitted than the larger population of evaluatees.

\section{Demographic characteristics.}

Age. The literature review indicated that relationships between age and CR findings have been mixed (Boehnert, 1987; Cirincione et al., 1995; Daniel et al., 1984; Johnson et al., 1990; Packer, 1987; Pasewark et al., 1987; Rogers et al., 1984; Warren et al., 2004). Here, I found a relatively consistent pattern, even when including non-psycholegal cases, that older individuals were more often classified insane. The only instance in which a "sane" subsample was older than the "insane" sample was in Linhorst and Turner (1999), which used a civil inpatient sample to represent "sane" cases. Individuals with severe and persistent mental illness, such as schizophrenia, who are in their 30s and 40s more often present for emergent psychiatric treatment (Albert \& McCaig, 2015). As such, it would be expected that civil psychiatric groups would be relatively older than forensic samples. On the other hand, Moskowitz et al. (1999) also utilized a civil psychiatric sample. It is unclear why, unlike Linhorst and Turner, Moskowitz and colleagues found their acquitted subsample was older than their inpatients.

Even after non-psycholegal comparison groups were removed, high heterogeneity across studies remained across age analyses, which suggested the variability was due to methodological 
differences. Johnson et al.'s (1990) study had the largest disparity in age between subgroups. Notably, the authors' subgroup of defendants found insane was quite small and the confidence interval was broad, which together suggests the study may not generalize to other CR samples. It is uncertain which study-level characteristics contributed to the differences in effect sizes. Nonetheless, a general trend was still identified: older individuals are more likely than younger individuals to be opined insane than sane.

Sex. Although the overall summary effect for the sex-insanity outcome relationship was not significant, subsequent analyses revealed that at least among evaluation and trial samples, females were more likely to be opined insane. This latter finding was robust: all psycholegal samples found this relationship. No significant heterogeneity was identified, meaning variations in effects within this particular analysis were likely due to chance rather than methodological differences. This could be because "sex" is clearly defined, and so there would be no opportunities for subjective variable definitions, as was seen among treatment and criminal history variables. Consistent operationalization of sex across studies likely reduced heterogeneity and inconsistency in this case.

As expected then, the summary effect of sex for psycholegal samples is consistent with the lion's share of past research (e.g., Cirincione et al., 1995; Warren et al., 2004). One previous study (Rogers et al., 1984) identified no effect for sex among its results; however, this study was not eligible for the present analysis because it did not provide sufficient data to provide calculable effect sizes. This highlights the importance of providing comprehensive statistics (e.g., $n$ s, $M, S D$, appropriate effect size statistics) in published reports. Regardless, many studies would be required to negate this summary effect, and so it is unlikely that Rogers et al. or even several other studies with null effects would change this relationship. 
Importantly, however, there are no reasons aligned with psycholegal theory for which females should be more often opined insane than their male counterparts. It could be that females are, in general, perceived as less culpable for their actions relative to males. They may also be more likely than males to carry factors that increase their likelihood of being opined insane. This speculation is supported by national data indicating females experience more serious psychiatric problems than males (Weissman, Pratt, Miller, \& Parker, 2015). In addition, Caldwell et al. (2003) found that females in their CR study were more likely to be diagnosed with psychotic disorders than males. Further, although Warren et al. (2004) originally found females were at an increased likelihood to be opined insane, these findings dissipated at the multivariate level. Thus, the relationship between female sex and insanity may be facilitated by clinical factors.

Race. There was no initial significant summary effect for race, and effect estimates did not vary according to whether or not non-psycholegal groups were taken into consideration. There was a range of effect sizes, with Powell (1998) and Warren et al. (2004) finding statistically significant relationships, but in alternate directions. However, while both utilized referred samples, Powell operationalized outcomes according to ALI criteria, while Warren et al. followed M'Naghten. In general, the notable heterogeneity across race studies might be explained by varying study-level characteristics, such as publication type, type of comparison group, and legal tests.

Still, at least among the studies incorporated into this meta-analysis, race does not appear to consistently impact overall CR outcomes. This is encouraging, as there is no compelling reason for a particular race to more often be opined insane. Research has been mixed on this defendant characteristic, and it is likely that other variables better account for the effects of race on CR outcomes. In line with this speculation, researchers (Rogers et al., 1984; Warren et al., 
2004) who incorporated race and clinical characteristics into multivariate models have found that diagnosis may subsume the effects of race on insanity outcomes.

Education. Three psycholegal studies were available to calculate a summary effect for high school completion. The finding was significant, in that defendants who graduated high school were more likely to be opined insane compared to defendants who did not reach this level of educational attainment. Publication bias was unlikely. Several additional studies not eligible for these analyses found similar relationships (Cirincione et al., 1995; Daniel et al., 1984; Rogers et al., 1984), which increases confidence in the summary effect. This finding is somewhat counterintuitive, as it could be assumed that failure to graduate high school would be linked to greater psychiatric impairment. Then again, the onset for severe and persistent mental illnesses, such as schizophrenia, most often occurs in late adolescence or early adulthood - after a typical individual would be expected to graduate high school (American Psychiatric Association, 2013). It is unclear why further education is associated with increased likelihood of an insanity opinion.

Employment. Only psycholegal samples provided data for the employment analyses.

Unemployed defendants were significantly more likely to be opined insane. This aligns with data indicating individuals with severe and persistent mental illness are less likely to hold employment (Luciano \& Meara, 2015). In forming insanity opinions, evaluators and fact-finders may look to unemployment as a marker of functional impairment when assessing defendants' psychiatric status. Notably, there was very little heterogeneity identified across studies, indicating that methodological factors did not play significant roles in estimating the summary effect. The degree of publication bias reflects the range of effect sizes in these analyses. Sample characteristics may be particularly influential in this case. Boehnert (1989) only included males in her sample, while Boardman (1996) and Pasewark et al. (1987a) incorporated females. Given 
that females are less likely to hold employment (U.S. Bureau of Labor Statistics, 2017) and, as previously identified, females are more often opined insane, female sex may be influencing this relationship.

Marital status. Unlike employment status, marital status was not significant in differentiating sane and insane cases. However, the lack of a significant summary effect may be for several reasons, primarily methodological considerations. Heterogeneity analyses were significant and revealed high inconsistency across studies. Indeed, study-level characteristics varied on particularly relevant variables: one sample was comprised of all males, another of all females, and one consisted of a civil psychiatric group. Females with severe and persistent mental illness are more likely to marry than their male counterparts (Nyer et al., 2010). It could be that samples consisting entirely of a particular sex could muddy the summary effects for marital status. However, heterogeneity was still notable even after removing non-psycholegal cases from the analyses. The two that remained were both dissertations similar on subsample type and legal criteria, and so differences in effects may be attributed to unknown factors.

\section{Clinical characteristics.}

Treatment history. This variable served as a proxy for severity of mental illness and, as expected, strongly predicted insanity outcomes. Significant heterogeneity across studies was identified. This is likely due in part to the variability in how authors operationalized prior psychiatric treatment. Pasewark et al. (1987b) was a notable outlier: in their study, all insane defendants had prior psychiatric treatment. However, the authors defined past treatment as encompassing inpatient or outpatient treatment, a more inclusive operational definition than adopted by other researchers. It is probable that inpatient hospitalization better captures more severe mental illness than outpatient treatment history. For example, those with one prior 
outpatient treatment session and no inpatient hospitalizations are likely quite different from defendants who attended outpatient treatment and had past hospitalizations; meaning, this second hypothetical defendant has likely experienced significantly more impairment due to mental illness. In line with this speculation, Boardman (1996), who used outpatient treatment to operationalize treatment history, was the only study not to find a significant relationship between past treatment and insanity. Regardless, we can assume that overall, defendants with a history psychiatric treatment were more likely to be opined insane in this study.

Diagnosis. Of all study variables, researchers most frequently attended to psychiatric diagnosis. The summary effect that defendants diagnosed with psychotic disorders were more often opined insane was a robust finding. Hays (199), Linhorst and Turner (1999), and Moskowitz et al. (1999) were the only studies not to demonstrate this significant effect. Given that these studies used psychiatric samples as their "sane" comparison groups, significant differences in diagnoses across "sane" and "insane" subgroups would not be anticipated. It would be expected that most individuals in psychiatric settings would carry a serious mental health diagnosis such as psychosis, and therefore share similar diagnoses with successful acquittees. Indeed, the strength of the psychosis-insanity relationship increased after removing non-psycholegal groups from the analyses.

These findings supported primary study hypotheses and are in line with psycholegal theory. However, marked heterogeneity was present in both pre- and post-sensitivity analyses, providing strong evidence that variability in summary effects were due to study methods instead of sampling error. Very likely, varying definitions of "psychotic disorder" contributed to this heterogeneity. Other methodological considerations may have played a role. For instance, Nestor and Haycock (1997), who found a remarkable relationship between diagnosis and CR outcome, 
matched defendants on age, crime type, and IQ. This approach may have accounted for other factors that could confound the diagnosis-insanity relationship. Given that several thousand null findings would be needed to negate the robust summary effects for diagnosis, there is adequate assurance that diagnosis of a psychotic disorder is a strong predictor of insanity outcomes.

It is important to underscore that only studies clearly documenting diagnosis of a psychosis were included in these analyses. Further, we were only able to code for primarymeaning singular-diagnosis. In clinical practice, defendants frequently carry more than one diagnosis. Take, for an example, a defendant diagnosed with psychotic disorder and a substance use disorder who was under the influence of a substance at the time of the offense. While the defendant may have been asymptomatic with respect to psychotic symptoms during that time, active substance use may have had an additive effect, and acted as the primary driver behind the criminal act. Given that defendants typically cannot be found insane primarily based on the influence of voluntary intoxication (State v. Hall, 1974), the defendant in this scenario would likely be opined sane. Coding only for primary diagnosis (psychotic disorder) in such cases would mask important, "real world" clinical implications. Unfortunately, then, findings here may not best translate to actual clinical practice.

\section{Legal characteristics.}

Criminal history. Overall, individuals without a criminal history were much more often classified insane. This was not the case in Moskowitz et al. (1999), potentially because civil inpatients were less likely to have criminal histories than justice-involved subsamples. Moderate heterogeneity was revealed, which could be explained by variability across studies in the definition of this defendant characteristic. As mentioned previously, authors operationalized criminal history from simply "prior arrest" to "prior felony conviction." Therefore, it would be 
expected that this methodological consideration would produce different summary effects across studies, above and beyond those produced by chance. Packer's (1987) effect size was more than double the effect size of others' studies. A notable difference is that in Packer's study, all cases were charged with murder. Serious crimes committed by defendants with a past criminal history may be rooted in antisocial character pathology, which can exclude a defendant from a successful insanity defense. Conversely, serious crimes committed by those without a criminal history, coupled with serious mental illness, could be borne out of disorganized thinking or behavior and meet criteria for insanity. Despite the moderate heterogeneity, it is nevertheless evident that criminal history in general reduces the likelihood defendants will be found insane.

Violent instant offense. Violent charges had no significant relationship with CR outcomes. Potentially, this null finding could be due to the manner in which authors categorized offense type. While some delineated specific crimes (e.g., Powell, 1996), others dichotomized crimes into violent/non-violent. It could be that researchers differed in their assignment of "violent," particularly for crimes such as arson or robbery in which no one is injured, but are considered violent nevertheless. The marked heterogeneity among studies assessing the impact on CR provides some support for this speculation. Of course, the studies also varied in publication type, comparison group (evaluation/trial), and legal tests, which could also influence offense-outcome relationships.

Competency evaluation history. Emerging data indicates defendants evaluated for CST and CR are more likely to be opined insane by evaluators (Chauhan et al., 2015). This pattern did not replicate here exactly on account of Pasewark et al. (1987b). Of note, it could be that all defendants in Pasewark et al.'s (1987b) study were referred for CST evaluations — indeed, all but four defendants were provided a CST opinion — but the authors did not explicitly state this in 
their methodology. Should Pasewark et al. (1987b) be removed from these analyses, the summary effect would be significant in that defendants referred for CST evaluations were more likely to be found insane. This suggests that, when combined CST and CR evaluations are not standard practice, defendants evaluated for combined evaluations are perceived by the referral source as impaired, a finding replicated by the courts at trial.

Incompetency history. The finding that defendants opined incompetent to stand trial were more likely to be opined insane was the most robust effect throughout the analyses, even more so than diagnoses. Although effect sizes were variable, we know that overall, consistent with past research (Daniel et al., 1984), the association between incompetency and insanity is strong. Importantly, the majority of studies within this area incorporated defendants who plead insanity at trial; hence, many were once deemed incompetent, restored, and then moved forward with trial. Only Johnson et al. (1990) examined defendants referred for these evaluations without considering trial outcome. Of note, defendants in Johnson's study may have been incompetent and not restored, and so their insanity defense was never officially raised.

\section{Study Space Findings: Reviewing the Research}

Typically, the objective of a study space is to identify specific variable combinations for future research. As Malpass et al. (2008) noted, the call for research resulting from study spaces should be systematic, instead of calling simply for "more." However, it was quite clear that according to eligibility criteria, very few variables have been studied in combination and that replication studies for all demographic, clinical, and legal variables are warranted. Most notably, no studies assessed variable relationships in the context of ALI/evaluator characteristics. As a result, no variables of interest have been researched across the four CR outcomes available. Not a single eligible study considered marital status, although it is recognized this variable is likely 
not a primary factor driving defendants' CR status. Of note, the majority of studies in the study space incorporated males. As speculated in the meta-analytic findings, the impact of sex may be relevant here. The heterogeneity and inconsistency identified among meta-analytic findings provided support that study-level characteristics appear to impact variable-outcome relationships. Given that there were very few studies to begin with, it is evident that methodology was not consistent across studies and we likely do not yet have a clear picture of the CR research landscape.

\section{Implications for Research}

While this project may not have provided as much clear direction as anticipated, it provides ample opportunity for new directions in research. Regarding the meta-analysis, clear and consistent summary effects are ideal; however, illuminating effect heterogeneity is just as important and contributes to our understanding of the relevance of methodological considerations in CR research. Parsing out predictor variables and the four potential outcomes of CR inquiry via the study space further revealed research questions that warrant attention.

A continuing challenge for $\mathrm{CR}$ investigators is conducting research with relatively small samples. Those working in the public sector may consider developing inter- or intra-state CR research databases, as has Warren and colleagues, in order to garner large numbers of defendants for study and to share data among research groups. Doing so would help to alleviate problems related to small sample size and consequently enhance statistical power. With ample defendants for study, researchers can update this body of literature. The most recent eligible study for this project was published 12 years ago, while the most recent data collection, on average, occurred 20 years ago. This likely reflects the period of burgeoning CR research that took place in the 1980s. Still, public attitudes and legislative reform regarding CR continue to shift, and research 
should reflect this movement. It would have been ideal to conduct a cumulative effects metaanalysis to understand how our knowledge of insanity has changed overtime. Unfortunately, to take a cumulative approach here would be misleading being that most data were collected over many years and publication dates do not necessarily reflect years of data collection. In moving forward with the CR research agenda, future researchers may find the following recommendations useful.

Explore spurious findings and heterogeneity. Fail-safe $N$ s evidenced the significant relationship between employment and insanity was tenuous. It may be worthwhile to further assess this association, especially given the small number of females incorporated into that specific set of analyses. Aside from this particular dyad, for most predictor-outcome relationships, strong summary effects were evident. However, there were marked between-study heterogeneity and inconsistency. As such, it can be assumed that the population of CR studies does not demonstrate uniform effects and differences can be attributed to study methodology in addition to study error. It is worth setting out to clarify patterns of findings and how specific methodological decisions impact the research. This task would help find meaning among seemingly arbitrary findings.

Provide consistent variable definitions and documentation. During the coding process it became clear that detailed variable operations would not be an option for these analyses, in light of the many ways authors defined research variables. Recall there was a range of definitions for "treatment history" and "criminal history." This inconsistency may have impacted study findings (e.g., Boardman, 1996 as compared to Pasewark et al., 1987b). As recommended by Zapf et al. (2011), it would be instructive to follow standardized means of measurement for these variables. Specifically, Zapf and colleagues recommended the Cormier-Lang system (Quinsey, 
Harris, Rice, \& Cormier, 1998) as a way to document criminal history. Somewhat similar, it would be informative to utilize a standardized measure of psychiatric symptoms, such as the Brief Psychiatric Rating Scale (BPRS; Overall \& Gorham, 1962). Such a step would prove particularly useful as diagnostic criteria for disorders evolve over time.

However, consistent operational definitions are futile if the data are not reported. Several studies were excluded from the meta-analyses as data were insufficient for calculating effect sizes (e.g., ORs or Cohen's $d$ ). Several research groups mentioned that certain analyses were "not significant" but offered no other detail. This is unfortunate, as the statistics field has moved away from placing most importance on $p$ values and instead on gauging effect sizes. That being said, the average study publication year was over 20 years ago, when there was not such an expectation that raw data or effect sizes should be reported. Today, more and more journals are requiring authors to report effect measures, which could help remedy this problem.

Somewhat similar, peer-reviewed research holds the most credibility and is more likely to meet admissibility standards than unpublished manuscripts. Four studies eligible for the metaanalysis were not eligible for the study space, as they were dissertations and therefore were not considered Daubert material. Peer-reviewed publication is encouraged, as this quality of literature is what most influences the research base.

Integrate clinical presentation and psycholegal ability variables. Hypotheses were supported that clinical variables would be heavily researched and strongly predict insanity outcomes. Still, diagnosis alone is a broad construct. Clinical presentations can be heterogeneous even within specific diagnoses. Therefore, it would be beneficial for researchers to incorporate defendants' clinical presentation at the time of the offense into research: specifically, whether or not defendants presented with delusions, hallucinations, or disorganized speech or behavior. 
Although it may be difficult to ascertain with certainty a defendant's retrospective presentation, good collateral data can provide some insight. In addition, impaired versus intact psycholegal abilities should be noted. Thus far only Warren and colleagues' group has closely considered psycholegal abilities related to insanity (Warren et al., 2004), although they did not directly compare defendants opined sane or insane on these variables.

Utilize appropriate comparison groups. Comparison groups should be appropriate for the research question at hand. For significant effects, all relationships grew more robust once non-psycholegal cases were removed from the analyses. Therefore, findings here indicated that when researchers have the intention of comparing "sane" and "insane" cases, only defendants evaluated for or who plead insanity should be considered. It is probably safest for evaluators, researchers, and legal professionals to rely on findings based on psycholegal samples as opposed to overall summary effects. This recommendation is in line with Zapf et al.'s (2011) observation that to use incarcerated or psychiatric subsamples in CR research is to neglect important defendant characteristics. In the same vein, researchers should further incorporate female defendants, who comprised only a small fraction of cases for the meta-analyses.

Conduct multivariate models. Ideally, meta-analyses include moderator (subgroup) analyses, accompanied by meta-regression to explore significance among study effect sizes. Unfortunately, limited sample size prohibited multivariate analyses here. As a result, the statistical significance of study-level characteristics' influence could not be delineated. Once the research base is adequate, future meta-analysts should consider conducting multivariate models in order to account for overlap in predictor variables, and thereby elucidate which variables best predict CR outcomes. 


\section{Implications for Practice}

At present there are few recommendations for specific clinical or legal practice, the reason being notable heterogeneity was identified within nearly all summary effects. Still, there are several findings that appear reliable. Those most relevant to practitioners' work include treatment history and diagnosis, which they can use to support their CR opinions. In their clinical work, practitioners might cite the finding indicating defendants with a treatment history are more often classified as insane. On the one hand, this could support a diagnosis of ongoing severe and persistent mental illness and its potential impact on psycholegal abilities. On the other, the same citation may be referenced in cases where defendants have no treatment history-until only after their alleged crime — and are suspected of malingering. Overall, however, practitioners should rely on summary effects with caution and with the caveat that many of the bivariate relationships identified in the meta-analysis dissipate once entered into multivariate models by other researchers (e.g., Rogers et al., 1984; Warren et al., 2004).

\section{Project Strengths and Limitations}

Many of the limitations of this meta-analysis are inherent criticisms of meta-analyses in general (Borenstein et al., 2009). To begin, meta-analyses are presumably biased in the direction of identifying significant relationships among variables, as authors are more likely to submit significant findings for publication and published materials are more readily available to metaanalysts than "file drawer" (i.e., nonsignificant) data. Although conference presentations were not included in the current analyses, grey literature in the form of unpublished dissertations were incorporated, a specific approach taken by "gold standard" social science meta-analysts (see Hopewell, Clarke, \& Mallett, 2005). The literature search was systematic and judged as thorough by an expert CR researcher in the field. Fail-safe Ns were calculated to provide an estimate of 
potential publication bias for each summary effect, which helped to assess the stability of given effects. In taking these steps, the likelihood of publication bias was likely reduced.

A significant concern here is that important studies in the CR literature were dismissed. This is a common problem in meta-analyses, given their stringent eligibility criteria and requirement that effect sizes can be calculated from a report's available data. For example, Cirincione et al. (1995), a report that has been cited 24 times according to the PsycINFO database, did not provide sufficient data for our coding protocol and therefore was ineligible for this study. It should be noted that Veysey (1993) utilized the same dataset as Cirincione et al., however, Veysey's report was an unpublished dissertation, and therefore does not carry the same credibility as Cirincione et al.'s published, peer-reviewed manuscript. A similar scenario took place for Rogers and colleagues' frequently-cited work (e.g., Rogers et al., 1984), although their data were not accounted for by an unpublished manuscript.

Another common criticism of meta-analyses is the "apples and oranges" analogy; that is, combining various study methodologies in order to calculate summary effects. Those who argue this position state it is incorrect to subsume different methods and operational definitions under the same "umbrella" (summary effect) analyses. This becomes particularly problematic when only a small number of reports are eligible for study, as was the case in this project. Given the low base rate of insanity pleas, it is not surprising that the number of studies meeting criteria for the meta-analysis was low. Unfortunately, the small sample size significantly limited statistical analyses. I could not sufficiently parse out "apples and oranges" through moderator (subgroup) analyses given that too few studies were present. It was particularly disappointing that I could not compare summary effects according to CR legal tests. I approached this significant limitation by examining heterogeneity via $Q$ and $I^{2}$ statistics. In addition, I underscore that as sample sizes 
were small, summary effects, particularly those with low fail-safe Ns, should be interpreted with great caution. As identified by measures of heterogeneity and by the study space, there are many methodological facets to be considered that may impact CR outcomes. As such, we cannot assume that findings here generalize to other samples, or that summary effects are particularly compelling.

\section{Conclusion}

Opinions of insanity have a significant impact on all involved in criminal trials, and it is somewhat surprising that this area of research is neglected relative to other psycholegal constructs, even considering the small number of defendants who plead insanity. This project is the first to empirically evaluate insanity research, a topic that is particularly difficult to quantify given its many methodological considerations. Meta-analytic findings revealed that overall, defendants referred for evaluation and opined insane or who plead insanity at trial and are acquitted are more likely to be older, female, high school graduates, and unemployed. They frequently have an established psychiatric treatment history and are diagnosed with a psychotic disorder. These defendants typically do not have a criminal history and those who have been opined incompetent to stand trial in the past are at an increased likelihood of being opined insane. Results also indicated that methodological differences across CR studies have a significant impact on research outcomes, and the study space helped to identify areas for future research attention. 


\section{References}

Albert, M. A., \& McCaig, L. F. (2015). Emergency department visits related to schizophrenia among adults aged 18-64: United States, 2009-2011. Retrieved from: https://www.cdc.gov/nchs/data/databriefs/db215.pdf

American Law Institute. (1962). Model Penal Code, Philadelphia, PA: The Executive Office, The American Law Institute.

American Psychiatric Association. (2013). Diagnostic and statistical manual of mental disorders (5th ed.). Arlington, VA: American Psychiatric Publishing.

Blackstone, W. (1979). Commentaries on the laws of England (9th ed.). New York: Garland.

Boardman, A. F. (1996, June). A comparative investigation of insanity acquittees and unsuccessful insanity evaluatees. Dissertation Abstracts International, 56, 7038.

Boehnert, C. E. (1987). Characteristics of those evaluated for insanity. Journal of Psychiatry \& Law, 15(2), 229-246.

Boehnert, C. E. (1989). Characteristics of successful and unsuccessful insanity pleas. Law and Human Behavior, 13(1), 31-39. doi:10.1007/BF01056161

Borenstein, M., Hedges, L., Higgins, J., \& Rothstein, H. (2005). Comprehensive Meta-analysis Version 2, Biostat, Englewood: New Jersey.

Borenstein, M., Hedges, L., Higgins, J., \& Rothstein, H. (2009). Introduction to meta-analysis. Chichester, UK: Wiley. 
Caldwell, R. M., Mandracchia, S. A., Ross, S. A., \& Silver, N. C. (2003). Competency to stand trial and criminal responsibility: An examination of racial and gender differences among African American and Caucasian pretrial defendants. American Journal of Forensic Psychology, 21(3), 5-19.

Chauhan, P., Warren, J., Kois, L., \& Wellbeloved-Stone, J. (2015). The significance of combining evaluations of competency to stand trial and sanity at the time of the offense. Psychology, Public Policy, And Law, 21(1), 50-59. doi:10.1037/law0000026

Cirincione, C., Steadman, H. J., \& McGreevy, M. A. (1995). Rates of insanity acquittals and the factors associated with successful insanity pleas. Bulletin of the American Academy of Psychiatry \& the Law, 23(3), 399-409.

Cochrane, R. E., Grisso, T., \& Frederick, R. I. (2001). The relationship between criminal charges, diagnoses, and psycholegal opinions among federal pretrial defendants. Behavioral Sciences \& the Law, 19(4), 565-582. doi:10.1002/bs1.454

Cohn, L. D., \& Becker, B. J. (2003). How meta-analysis increases statistical power. Psychological Methods,8(3), 243-253. doi:10.1037/1082-989X.8.3.243

Cooper, H., DeNeve, K., \& Charlton, K. (1997). Finding the missing science: The fate of studies submitted for review by a human subjects committee. Psychological Methods, 2(4), 447 452. doi:10.1037/1082-989X.2.4.447

Daniel, A. E., Beck, N. C., Herath, A., Schmitz, M., \& Menninger, K. (1984). Factors correlated with psychiatric recommendations of incompetency and insanity. Journal of Psychiatry \& Law, 12(4), 527-544.

Daubert v. Merrell Dow Pharmaceuticals, Inc., 516 U.S. 869 (1993). 
Deffenbacher, K. A., Bornstein, B. H., Penrod, S. D., \& McGorty, E. K. (2004). A meta-analytic review of the effects of high stress on eyewitness memory. Law and Human Behavior, 28, 687-706.

Dusky v. United States, 362 U.S. No. 402. (1960)

Finkel, N. J. (1989). The Insanity Defense Reform Act of 1984: Much ado about nothing. Behavioral Sciences \& the Law, 7(3), 403-419. doi:10.1002/bsl.2370070309

Higgins, J., \& Green, S. (2011). Cochrane handbook for systematic reviews of interventions. West Sussex, England: John Wiley \& Sons Ltd.

Higgins, J. T., Thompson, S. G., Deeks, J. J., \& Altman, D. G. (2003). Measuring inconsistency in meta-analyses. BMJ: British Medical Journal, 327(7414), 557-560. doi:10.1136/bmj.327.7414.557

Hays, F. M. (1999, November). A comparison of persons found not guilty by reason of insanity and mentally disordered offenders in outpatient treatment using Rorschach and MMPI-2 data. Dissertation Abstracts International, 60, 2342.

Heilbrun, A. B., \& Heilbrun, M. R. (1989). Dangerousness and legal insanity. Journal of Psychiatry \& Law, 17(1), 39-53.

Howard, R. C., \& Clark, C. R. (1985). When courts and experts disagree: Discordance between insanity recommendations and adjudications. Law and Human Behavior, 9(4), 385-395. doi:10.1007/BF01044478

Howard, G. S., Maxwell, S. E., \& Fleming, K. J. (2000). The proof of the pudding: An illustration of the relative strengths of null hypothesis, meta-analysis, and Bayesian analysis. Psychological Methods, 5(3), 315-332. doi:10.1037/1082-989X.5.3.315 
Johnson, W. G., Nicholson, R. A., \& Service, N. M. (1990). The relationship of competency to stand trial and criminal responsibility. Criminal Justice and Behavior, 17(2), 169-185. doi:10.1177/0093854890017002002

Jones v. United States, 463 U.S. 354 (1983)

Linhorst, D. M., \& Turner, M. A. (1999). Treatment of forensic patients: An expanding role for public psychiatric hospitals. Health \& Social Work, 24(1), 18-26. doi:10.1093/hsw/24.1.18

Lipsey, M. W., \& Wilson, D. B. (2001). Practical meta-analysis. Thousand Oaks, CA, US: Sage Publications, Inc.

Luciano, A., \& Meara, E. (2014). Employment status of people with mental illness: National survey data from 2009 and 2010. Psychiatric Services, 65(10), 1201-1209. doi:10.1176/appi.ps.201300335

Malpass, R. S., Tredoux, C. G., Compo, N. S., McQuiston-Surrett, D., Maclin, O. H., Zimmerman, L. A., \& Topp, L. D. (2008). Study space analysis for policy development. Applied Cognitive Psychology, 22(6), 789-801. doi:10.1002/acp.1483

McGinley, H., \& Pasewark, R. A. (1989). National survey of the frequency and success of the insanity plea and alternate pleas. Journal of Psychiatry \& Law, 17(2), 205-221.

Melton, G. B., Petrila, J., Poythress, N. G., Slobogin, C., Lyons, P. J., \& Otto, R. K. (2007). Psychological evaluations for the courts: A handbook for mental health professionals and lawyers (3rd ed.). New York, NY, US: Guilford Press.

Melville, J. D., \& Naimark, D. (2002). Punishing the insane: The verdict of guilty but mentally ill. Journal of The American Academy of Psychiatry and The Law, 30(4), 553-555. 
Moskowitz, J. L., Lewis, R. J., Ito, M. S., \& Ehrmentraut, J. (1999). MMPI-2 profiles of NGRI and civil patients. Journal of Clinical Psychology, 55(5), 659-668. doi:10.1002/(SICI)1097-4679(199905)55:5<659::AID-JCLP12>3.0.CO;2-6

Nestor, P. G., \& Haycock, J. (1997). Not guilty by reason of insanity of murder: Clinical and neuropsychological characteristics. Journal of the American Academy of Psychiatry and the Law, 25(2), 161-171.

Nyer, M., Kasckow, J., Fellows, I., Lawrence, E. C., Golshan, S., Solorzano, E., \& Zisook, S. (2010). The relationship of marital status and clinical characteristics in middle-aged and older patients with schizophrenia and depressive symptoms. Annals of Clinical Psychiatry, 22, 172-179.

Overall, J. E., \& Gorham, D. R. (1962). The Brief Psychiatric Rating Scale. Psychological Reports, 10799-812. doi:10.2466/pr0.1962.10.3.799

Packer, I. K. (1987). Homicide and the insanity defense: A comparison of sane and insane murderers. Behavioral Sciences \& the Law, 5(1), 25-35. doi:10.1002/bs1.2370050104

Packer, I. K. (2009). Evaluation of criminal responsibility. New York, NY, US: Oxford University Press.

Pasewark, R. A., Bogenberger, P., Gudeman, H., \& Bieber, S. (1987a). Factors associated with the insanity adjudication. Journal of Police and Criminal Psychology, 3(3), 9-16.

Pasewark, R. A., Jeffrey, R., \& Bieber, S. (1987b). Differentiating successful and unsuccessful insanity plea defendants in Colorado. Journal of Psychiatry \& Law, 15(1), 55-71.

Pirelli, G., Gottdiener, W. H., \& Zapf, P. A. (2011). A meta-analytic review of competency to stand trial research. Psychology, Public Policy, and Law, 17(1), 1-53. doi:10.1037/a0021713 
Powell, S. W. (1998, September). Expert witnesses' formulations of opinions of criminal responsibility. Dissertation Abstracts International, 59, 1377.

Queen v. M’Naghten, 10 Clark \& F.200, 2 Eng. Rep. 718 (H. K. 1843).

Quinsey, V. L., Harris, G. T., Rice, M. E., \& Cormier, A. C. (1998). Violent offenders: Appraising and managing risk. Washington, DC: American Psychological Association

Rogers, R., Seman, W., \& Stampley, J. (1984). A study of socio-demographic characteristics of individuals evaluated for insanity. International Journal of Offender Therapy and Comparative Criminology, 28(1), 3-10. doi:10.1177/0306624X8402800102

Shen, F. X., Hoffman, M. B., Jones, O. D., Greene, J. D., \& Marois, R. (2011). Sorting guilty minds. New York University Law Review, 86(5), 1306-1360.

Snyder, H. N. (2012). Arrest in the United States, 1990-2010. Retrieved from https://www.bjs.gov/content/pub/pdf/aus9010.pdf

Sporer, S. L., \& Cohn, L. D. (2011). Meta-analysis. In B. Rosenfeld, S. D. Penrod, B. Rosenfeld, S. D. Penrod (Eds.), Research methods in forensic psychology (pp. 43-62). Hoboken, NJ, US: John Wiley \& Sons Inc.

State v. Hall, 214 N.W.2d 205 (1974)

Sreenivasan, S., Kirkish, P., Eth, S., Mintz, J., Hwang, S., Van Gorp, W., \& Van Vort, W. (1997). Predictors of recidivistic violence in criminally insane and civilly committed psychiatric inpatients. International Journal of Law and Psychiatry, 20(2), 279-291. doi:10.1016/S0160-2527(97)00008-3

Steadman, H. J., McGreevy, M. A., Morrissey, J. P., Callahan, L. A., Robbins, P. C., \& Cirincione, C. (1993). Before and after Hinckley: Evaluating insanity defense reform. New York, NY, US: Guilford Press. 
U.S. Bureau of Labor Statistics. (2017). 2015 Current population survey and 2024 employment projections. Retrieved from https://www.dol.gov/wb/stats/latest_annual_data.htm\#labor Veysey, B. M. (1994). Gender differences in the adjudication of criminal responsibility: Social pressures for gender role congruity. Dissertation Abstracts International Section A, 54, 595.

Warren, J. I., Rosenfeld, B., Fitch, W. L., \& Hawk, G. (1997). Forensic mental health clinical evaluation: An analysis of interstate and intersystemic differences. Law and Human Behavior, 21(4), 377-390. doi:10.1023/A:1024855118855

Warren, J. I., Murrie, D. C., Chauhan, P., Dietz, P. E., \& Morris, J. (2004). Opinion formation in evaluating sanity at the time of the offense: An examination of 5175 pre-trial evaluations. Behavioral Sciences \& The Law, 22(2), 171-186. doi:10.1002/bs1.559

Weissman, J., Pratt, L. A., Miller, E. A., \& Parker, J. D. (2015). Serious psychological distress among adults: United States, 2009-2013. Retrieved from https://www.cdc.gov/nchs/data/databriefs/db203.pdf

Zapf, P., Green, D., \& Rosenfeld, B. (2011). Competency to stand trial and criminal responsibility research. In B. Rosenfeld, S. D. Penrod, B. Rosenfeld, S. D. Penrod (Eds.), Research methods in forensic psychology (pp. 156-173). Hoboken, NJ, US: John Wiley \& Sons Inc. 